\title{
Research on Stability of an Open-Pit Mine Dump with Fiber Optic Monitoring
}

\author{
Tao Zhigang $\mathbb{D},{ }^{1,2}$ Zhu Chun $\mathbb{D},{ }^{1,2,3}$ Wang Yong, ${ }^{1,2}$ Wang Jiamin $\mathbb{D}^{1,2}$ He Manchao, ${ }^{1,2}$ \\ and Zhang Bo ${ }^{1,2}$ \\ ${ }^{1}$ State Key Laboratory for Geomechanics \& Deep Underground Engineering, Beijing 100083, China \\ ${ }^{2}$ School of Mechanics and Civil Engineering, China University of Mining \& Technology (Beijing), Beijing 100083, China \\ ${ }^{3}$ College of Construction Engineering, Jilin University, Changchun 130026, China
}

Correspondence should be addressed to Zhu Chun; zhuchuncumtb@163.com

Received 16 June 2018; Revised 17 August 2018; Accepted 26 August 2018; Published 30 October 2018

Academic Editor: Luigi Borrelli

Copyright ( 2018 Tao Zhigang et al. This is an open access article distributed under the Creative Commons Attribution License, which permits unrestricted use, distribution, and reproduction in any medium, provided the original work is properly cited.

\begin{abstract}
China has over 1500 open-pit mines and 5000 dumps consisting of waste rock from the mining process. Due to dump instability in an open-pit mine and its diverse foundations, landslides and mudslides frequently occur. Heaped loose waste rock and concentrated heavy rainfalls are the two important factors affecting slope stability of a dump. Using the high Dump II within the Nanfen Open-Pit Iron Mine with a slope height of $300 \mathrm{~m}$ as a case study, this paper first proposes a physical model similarity ratio according to the on-site engineering geological survey data. The governing principles of deformation in the shallow dump layers in terms of different heaped loads and rainfall were then determined using fiber optic sensing to conduct an experimental study on the monitoring of the dump stability with an indoor physical model. Experimental results confirm that the amount of rainfall and heaped load has a great impact on the landslide in a dump. With an increase in the amount of material heaped onto the pile, the place between two heaped load points is squeezed and slowly deformed. As rainfall begins, the deformation of the rock-soil mass is significant, and constantly increasing rainfall intensity is accompanied by a dangerous sliding surface. Finally, the FLAC3D method was used to simulate the deformation features in the shallow part of Dump II under different heaped load conditions and verify the experimental results of the indoor physical model. By comparing the physical model experiments and numerical simulation results, we propose monitoring the stability of Dump II using this fiber optic sensing technology and provide the scientific basis for stability monitoring of similar dumps to detect the early warning signs of mudslides or landslides.
\end{abstract}

\section{Introduction}

Open-pit mines are prolific throughout China, generating enormous amounts of stripped, exploited, and discarded rocks. Stripped rock-soil mass materials are stacked in a dedicated place, which is called the dump [1]. Typically, $30 \%$ to $50 \%$ of the total land used by open-pit mines is occupied by dumps, so constant improvement of the dumping capacity and safety is important to improve productivity of the mine. Landslides and mudslides constantly occur and significantly affect the safety of dumping operations. As the mining process continues to advance, safety production operations in open-pit mines will always be affected by the slope stability of quarries and dumps [2]. Research on the slope stability of dumps is of important significance for the safety and economic benefits of mines [3].

A dump is a special engineered rock-soil mass consisting of discarded mixed soil and rock from quarries and created through stacking the materials. The spatial distribution of the dump, slope of the surface, height of slope sediments, strength of mixed materials, depth of slope water, and other factors all affect the stability of the dump slope [4-11]. The main disaster that affects dumps is landslides, and the key for preventing landslides is to control the slope stability of the dump. The main factors affecting dump slope stability are mechanical strength of loose rock-soil in the dump (friction strength parameter $c$ and $\varphi$ ) and characteristic parameters of drainage and seepage of granular particles, 


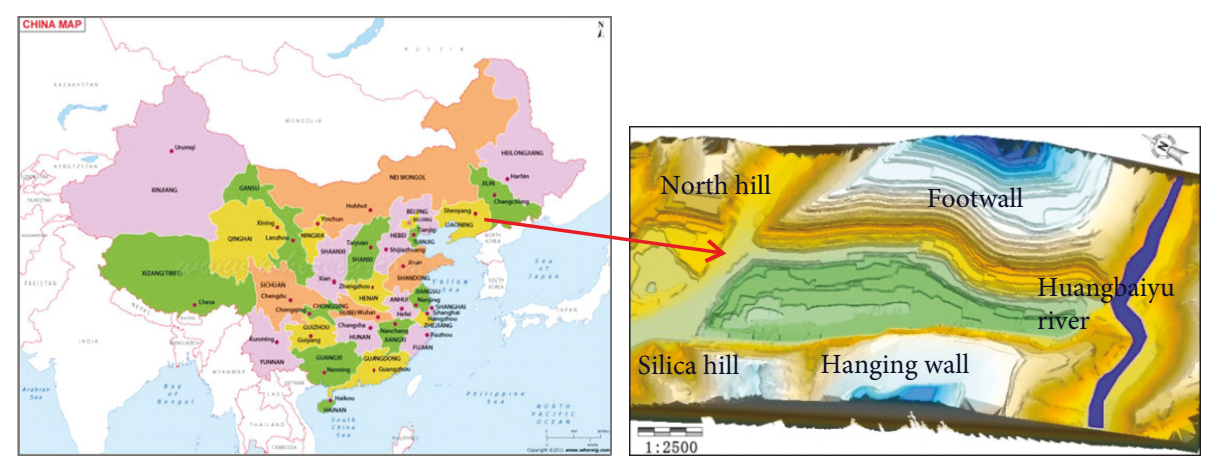

FIgURE 1: Location and satellite maps of the Nanfen Open-Pit Iron Mine.

topography, base lithology, discharge of surface water, groundwater flow, form of the dump slope, process and parameters of dump stacking, and shock caused by construction and earthquakes. In general, these factors can be divided into four categories: external force, physical and mechanical properties of the base, physical and mechanical properties of dumping materials, and the impact caused by water. Disasters affecting dumps can be effectively prevented if influence from these four aspects can be well controlled.

Compared to rock slope problems, research on the stability of dumps started just recently in the 1980s with the development of open-pit mine dump engineering, including methods and theoretical technology for ensuring slope stability. Research on dumps has determined the granular structure, landslide mechanisms, and other aspects based on features and methods of slope stability research, thus forming a complete basis for research on and analysis methods for dump stability.

Dump stability has been extensively analyzed [12-18]. Combined with geological features of the dump, the effects of blasting shock caused by mine production on the slope stability of the dump have been determined [19]. Field measurement units and a recording system were constructed and installed in a waste-dump slope at the Imgi mine to analyze the variation of conditions in unsaturated soil [20]. To investigate the effects of vegetation on runoff and erosion, a field experiment involving eight erosion plots was conducted on a dump at the Antaibao opencast coal mine in Shanxi Province [21]. In order to estimate the failure mode of sliding, numerical simulations on the failure mechanics of dumps were performed using FLAC3D, and a physical model test on the failure processes of dumps was performed using a floor friction model [22]. In order to maintain longterm protection of the environment, one study explored the possibilities of using local species for the mechanical stability of the waste dump in a surface iron ore mine [23]. For wastedump slopes that form basements, landslides can be prevented by determining the stability evolution principles of dynamic development, and the relationship between the mechanical structure and stability of waste dumps with basements has previously been studied [24].

As the amount of deformation of the dump slope is much larger than that of an ordinary rock slope, it is difficult for conventional slope stability monitoring techniques and methods to be effectively applied to dump slope monitoring
$[25,26]$. In terms of dump slope stability monitoring techniques and methods, surface cracks, collapses, land subsidence, and other anomalies are observed in the early period before the actual landslide through manual inspection. After the first observed surface anomalies, new methods, such as theodolite for surface displacement monitoring, total station, levels, and GPS monitoring, can be used. However, these methods are based on point monitoring, which cannot achieve long-distance and large-area monitoring, and have blind zones. Although the reliability can be improved by increasing monitoring points, monitoring costs will also greatly increase, and the increase in monitoring points will affect the integrity and structural safety of monitored rock-soil mass. Also, dumping of the material is a dynamic working process, and surface displacement will constantly change throughout, which will lead to frequent early warnings and cannot accurately provide an early warning of landslides or mudslides.

To address some of these issues, this paper uses Dump II located in the Nanfen Open-Pit Iron Mine in Northeast China as a case study. Fiber optic sensing technology was adopted to perform comparative analysis on the evolution features of dumps under different working conditions. Through the combination of the fiber optic monitoring of indoor physical model experiments and numerical simulations of the stability of the dump, a theoretical and practical foundation is laid for fiber optic monitoring solutions of a mine dump.

\section{Regional Geological Survey of Dump II}

2.1. Topography. The Nanfen Open-Pit Iron Mine is located in Benxi City, Liaoning Province, of Northeast China [27]. The Eastern boundary spans longitude $123^{\circ} 50^{\prime}$, and the northern boundary traverses latitude $41^{\circ} 07^{\prime}$. The mine is a monocline structure mainly composed of metamorphic rock strata, alpine glaciation landforms forming the surface, with an east-west strike (Figure 1). Gullies crisscross the landscape with relatively less vegetation coverage and steep hilltop slopes. The elevation of the general mountains near the mine reaches $500 \mathrm{~m}$ to $600 \mathrm{~m}$, with the highest peak at $963 \mathrm{~m}$ and the lowest at $296 \mathrm{~m}$, a relative height difference of $667 \mathrm{~m}$. In the southwestern area of the mine, the relative height is $300 \mathrm{~m}$ to $400 \mathrm{~m}$ with surface vegetation currently being developed. 
TABLE 1: Strength parameters of Dump II.

\begin{tabular}{lcccc}
\hline Lithology & & & Parameter \\
& State & Density $\left(\mathrm{kg} \cdot \mathrm{m}^{-3}\right)$ & Cohesion $(\mathrm{C} / \mathrm{kPa})$ & Internal friction angle $\left(^{\circ}\right)$ \\
\hline Flint limestone & Natural & 2650 & 670.0 & 40.0 \\
Green-purple sandy shale & Natural & 2600 & 620.0 & 32.0 \\
Dark-purple mica shale & Natural & 2580 & 490.0 & 27.8 \\
Gray fine quartz sandstone & Natural & 2680 & 760.0 & 40.2 \\
Crystalline limestone & Natural & 2650 & 670.0 & 40.0 \\
Egg-green marl & Natural & 2580 & 8.0 & 27.8 \\
& Natural & 1800 & 10.0 & 30.0 \\
Quaternary residual slope deposit & Saturated & 1920 & 20.0 & 28.0 \\
Dumping materials (slag discharged & Natural & 2100 & 45.0 & 35.0 \\
from the hanging side of the mine) & Saturated & 2250 & 40.0 & 30.0 \\
Upper dumping materials (slag discharged & Natural & 2100 & 45.0 & 33.0 \\
from the heading side of the mine) & Saturated & 2250 & 25.0 & 30.0 \\
Middle dumping materials (slag discharged & Natural & 2100 & 50.0 & 34.0 \\
from the heading side of the mine) & Saturated & 2250 & 10.0 & 31.0 \\
Lower dumping materials (slag discharged & Natural & 2100 & 20.0 & 35.0 \\
from the heading side of the mine) & Saturated & 2250 & 80.0 & 32.0 \\
Debris accumulation & Natural & 2100 & 100.0 & 20.0 \\
& Saturated & 2250 & & 18.0 \\
\end{tabular}

TABLE 2: Key deformation parameters of granular waste rock.

\begin{tabular}{|c|c|c|c|c|}
\hline Lithology & Initial void ratio $(n)$ & $n$ & $\begin{array}{l}\text { Parameter } \\
\text { Compression modulus (MPa) }\end{array}$ & Poisson's ratio \\
\hline Upper dumping materials of the dump & 0.6 & $37.4 \%$ & 26.05 & 0.37 \\
\hline Middle dumping materials of the dump & 0.57 & $36.4 \%$ & 26.4 & 0.35 \\
\hline
\end{tabular}

The five original historical dumps have been combined into the three current dumps in the southwest, southeast, and northeast of the quarry, namely, Dumps II, IV, and V. The current Dump II, created by the merger of the original Dumps II and III, is located in the hanging side southwest of the quarry, which mainly uses an autocrushing-belt conveyor-dumping machine combined with the transportation and dump process to discard waste rock in the hanging side through an east-to-west "U"-shaped valley consisting of the Dadonggou and Fengjiadonggou gullies (Figure 2). Overall, the bottom of the Dadonggou and Fengjiadonggou gullies is high in the east and low in the west, and the elevation of the current valley below the slope foot of the dump changes from $330 \mathrm{~m}$ to $420 \mathrm{~m}$.

\subsection{Strata Lithology and Strength Parameters of Accumulation.} The main lithology of Dump II within the Dadonggou and Fengjiadonggou gullies consists of the Archean Anshan Group, Proterozoic Liaohe Group, Cambrian and Sinian strata, and Cenozoic Quaternary strata. Specifically, the strata consist of egg-green marl of the Nanfen Formation in the Sinian system, gray fine quartz sandstone from the Qiaotou Formation in the Sinian system, flint limestone of the Jianchang Formation in the Cambrian system, dark-purple mica shale of the Maozhuang Formation in the Cambrian system, crystal limestone of the Zhangxia Formation in the Cambrian system, and green-purple sandy shale of Xuzhuang Formation in the Cambrian system. Among them, the basic section of the internal foundation of the dump is mainly made of marl, and a few quartz sandstones appear in the southeast corner of the dump. The upper part of the dump is covered with a Quaternary slope diluvium layer varying in thickness from $0.0 \mathrm{~m}$ to $6.0 \mathrm{~m}$. The bearing capacity of the bed rock is mainly affected by the compressive strength of the bed rock and is related to the development of jointed fissures.

Based on the Code for Investigation of Geotechnical Engineering of China (GB50021-2001) and Specification of Soil Test of China (SL237-99), a large number of in situ direct shear field tests, indoor triaxial tests, indoor direct shear tests, and on-site push shear tests on Dump II in the Nanfen OpenPit Iron Mine were performed in April 2014 by the Institute of Rock and Soil Mechanics, Chinese Academy of Sciences. According to the particle size distribution law of various granular waste rock measured at the site, the sample was made in the laboratory. The indoor triaxial compression test and the direct shear test of the granular waste rock were carried out according to the bulk gradation scheme and the stress state, the physical and mechanical parameters of the bulk material in Dump II are comprehensively obtained, and their results are shown in Tables 1 and 2 . 
TABLE 3: Statistics of precipitation in the Benxi area.

\begin{tabular}{lccc}
\hline Indicator & Precipitation $(\mathrm{mm})$ & Indicator & Precipitation $(\mathrm{mm})$ \\
\hline Average annual precipitation & $848-856$ & Annual maximum precipitation & 1212.7 \\
Monthly maximum precipitation & 487 & Annual minimum precipitation & 518.5 \\
Daily maximum precipitation & 83 & Average annual evaporation & 1628.4 \\
Annual maximum evaporation & 1843.4 & Annual minimum evaporation & 1374.1 \\
\hline
\end{tabular}

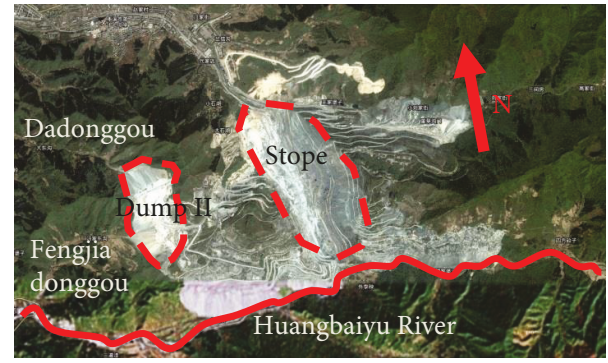

Figure 2: Mining area diagram.

2.3. Hydrogeological Features. The mine is located at midlatitude within a monsoon and continental climate. The precipitation in the flood season accounts for about $70 \%$ in the entire year, of which the precipitation in July and August accounts for about $50 \%$ of the annual precipitation with a relatively high temperature difference all year round (Table 3 ). The Miao'ergou River to the north and Huangbaiyu River to the south cross the area from east to west and are parallel to Zones 1 (Dadonggou; east) and 2 (Fengjiadonggou; west) of Dump II and located outside the region. There are no rivers feeding into the dump site. Water in the region is not currently under development.

Dump II is classified as a gully dump, and atmospheric precipitation is a major source of surface water and groundwater, with strong seasonal variations (April-August). Currently, the dump, in Zone 1 (Dadonggou), has a convergence area of $86 \times 104 \mathrm{~m}^{2}$ with a circumference of $3.7 \mathrm{~km}$; in Zone 2 (Fengjiadonggou), the convergence area is $97.5 \times 104 \mathrm{~m}^{2}$ with a circumference of $3.98 \mathrm{~km}$. According to the survey carried out by the Institute of Rock and Soil Mechanics, Chinese Academy of Sciences, the extent of the water distribution on the platform surface area of Dump II in the Nanfen Open-Pit Iron Mine is mainly from atmospheric precipitation. In addition, there is a layer of phreatic groundwater, and there is a layer of bed rock fissure water within the site. The groundwater burial depth is about 12.0 to $15.0 \mathrm{~m}$.

The waste rock in the dumping site is mainly composed of gravel, block stone, sand, and clay. The permeability coefficient is difficult to measure in an indoor test and is generally determined according to field testing. According to the site conditions, the test method for the permeability coefficient of the dumping site was performed using the preburied steel pipe method. According to local rainfall conditions, the on-site single-ring water injection tests were completed in the investigation area of Zone 1 (Dadonggou) and Zone 2 (Fengjiadonggou), according to the requirements of the Water Injection Test Procedure (YS5014-2000). The permeability coefficient of each zone can be calculated as

$$
\begin{aligned}
& \text { Zone } 1: K_{1}=1.92 * 10^{-2} \mathrm{~cm} / \mathrm{s}, \\
& \text { Zone } 2: K_{2}=1.65 * 10^{-2} \mathrm{~cm} / \mathrm{s} .
\end{aligned}
$$

\section{Fiber Optic Monitoring Indoor Physical Model Experiment of Dump II}

Currently, real-time monitoring and early warnings of landslides and mudslides in the dump are enormous problems. In terms of the regional geological survey of Dump II of the open-pit mine, it is urgent to adopt new technologies and new methods to monitor the deformation of Dump II in order to maintain a safe work environment and continue to develop the iron belt at this location. Based on the principle of distributed optical fiber monitoring and the occurrence mechanism of mudslide in the dump, the experimental study on Dump II with the fiber optic monitoring indoor physical model was performed.

3.1. Working Principle of the Distributed Optical Fiber Monitoring System. The basic measurement principle of the Brillouin optical fiber time domain analysis (BOTDA) is shown in Figure 3. BOTDA uses the Brillouin frequency shift caused by the Brillouin scattering light through stimulation. The shift is caused by changes in axial temperature and strain of optical fibers. Lasers need to be placed at both sides of the optical fiber, and continuous and pulsed light are injected into the optical fiber to create loop monitoring [28-33]. BOTDA demodulation equipment used in the indoor physical model experiment was the NBX-6050A fiber optic strain demodulator produced by Neubrex (Japan). This instrument can obtain a relatively strong signal from a highly scattered source, and its spatial resolution can reach up to $5 \mathrm{~cm}$ with an accuracy $7 \mu \varepsilon\left(0.3^{\circ} \mathrm{C}\right)$ with a monitoring distance of up to $20 \mathrm{~km}$. The instrument was set up to continuously collect data for real-time monitoring.

\subsection{Indoor Physical Model Test}

\subsubsection{Similarity Ratio Determination}

(1) Model and Particle Size Determination. This experiment used Dump II within the Nanfen Open-Pit Iron Mine as the example with the physical simulation method. The 


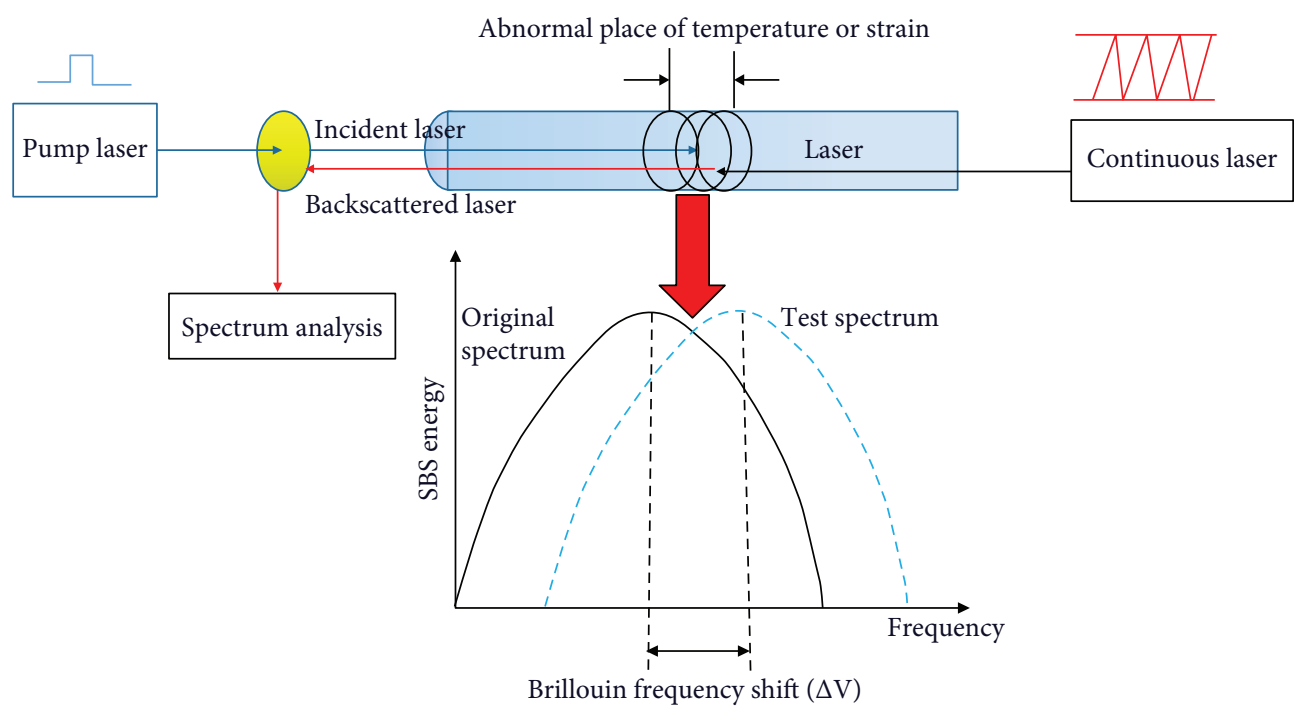

FIgURE 3: Basic principle diagram of BOTDA.

TABle 4: Content of each grade of dispersion in the dump (Fengjiadonggou).

\begin{tabular}{|c|c|c|c|c|}
\hline Particle group collectively & Particle g & sification & Particle size range $(d / \mathrm{mm})$ & Content (\%) \\
\hline \multirow{2}{*}{ Giant particle group } & \multicolumn{2}{|c|}{ Boulder (rock) } & $d>200$ & 5.50 \\
\hline & \multicolumn{2}{|c|}{ Pebble (gravel) } & $200>d>60$ & 17.72 \\
\hline \multirow{3}{*}{ Coarse grain group } & \multirow{3}{*}{ Gravel (breccia) } & Coarse gravel & $60>d>20$ & 27.15 \\
\hline & & Medium gravel & $20>d>5$ & 27.55 \\
\hline & & Fine gravel & $5>d>2$ & 10.91 \\
\hline \multirow{2}{*}{ Fine grain group } & \multicolumn{2}{|c|}{ Grit, powder } & $2>d>0.005$ & 10.38 \\
\hline & \multicolumn{2}{|c|}{ Clay particle } & $0.005>d$ & 0.80 \\
\hline
\end{tabular}

simulated similarity ratio was calculated according to the following formula:

Actual height of the dump slope $H_{1}$ The maximum particle size $D_{1}$ of the dump Simulated slope height $\mathrm{H}_{2}$

$=\overline{\text { The maximum particle size } \mathrm{D}_{2} \text { of the material used by the model }}$.

The following parameters were determined by summarizing and analyzing the current materials of Dump II:

(i) $H_{1}=250 \mathrm{~m}$ (Fengjiadonggou), $D_{1}=1000 \mathrm{~mm}$, and $H_{2}=1 \mathrm{~m}$; the largest volume of Dump II: $3800 \times 10^{4} \mathrm{~m}^{3}$

(ii) According to local rainfall statistics, annual precipitation is typically $847 \mathrm{~mm}$, the maximum annual precipitation is typically $1212 \mathrm{~mm}$, and the minimum annual precipitation is typically $518 \mathrm{~mm}$; the maximum flow of the basin in the rainy season is typically $110.5 \mathrm{~L} / \mathrm{S}$
In summary, $D_{2}$ can be obtained from formula (2):

$$
D_{2}=\frac{H_{2} \times D_{1}}{H_{1}}=4 \mathrm{~mm} .
$$

Therefore, the similarity ratio of the indoor physical model was set to $1: 250$, and the maximum particle size of the material used in the simulation was $4 \mathrm{~mm}$. According to the principle of similarity ratio, the content of each grade of on-site sieved dispersion (Table 4), and the similarity ratio, indoor experiment materials were matched to meet outdoor conditions of the dump, as shown in Table 5 .

(2) Determining Daily Maximum Precipitation. According to local rainfall statistics acquired by the local meteorological center, the daily maximum precipitation of the local area was set to $83 \mathrm{~mm}$, the rainfall area $s$ of the experimental model was $4 \mathrm{~m}^{2}$, and the hourly precipitation $v$ was $60 \mathrm{~L}$, and according to the experimental requirements, the rainfall time $t$ needed to be calculated when the indoor 
TABLE 5: Content of each grade of the indoor test.

\begin{tabular}{lccc}
\hline S/N & Particle size range $(d / \mathrm{mm})$ & Sieved quality $(\mathrm{g})$ & Content $(\%)$ \\
\hline 1 & $d>2$ & 98 & 6.7 \\
2 & $2>d>1$ & 238 & 16.46 \\
3 & $1>d>0.75$ & 437 & 30.15 \\
4 & $0.75>d>0.5$ & 379 & 26.18 \\
5 & $0.5>d>0.25$ & 123 & 8.52 \\
6 & $0.25>d>0.075$ & 163 & 11.26 \\
7 & $0.075>d$ & 10 & 0.73 \\
\hline
\end{tabular}

test reached the maximum daily precipitation was calculated as follows:

$$
t=\frac{p s}{v},
$$

where $t$ is the rainfall time/h, $p$ is the daily maximum precipitation of $83 \mathrm{~mm}, s$ is the precipitation area of $4 \mathrm{~m}^{2}$, and $v$ is the hourly precipitation of $60 \mathrm{~L}$.

The time needed to reach the maximum daily precipitation was calculated to be $5.5 \mathrm{~h}$. During the experiment, according to local rainfall conditions, rainfall occurred for $5.5 \mathrm{~h}$ for the first day, $5.5 \mathrm{~h}$ for the second day, and $5.5 \mathrm{~h}$ for the third day. The amount of strain endured by a single fiber optic due to rainfall was then compared across these three days.

3.2.2. Physical Model Construction. According to the similarity principle of the indoor physical model experiment compared to outdoor conditions, this experiment design was based on the physical similarity simulation. According to the similarity ratio of $1: 250$, the experimental model was set up to be $2 \mathrm{~m} * 2 \mathrm{~m} * 1 \mathrm{~m}$ with the slope top of $2 \mathrm{~m} * 0.5$ $\mathrm{m}$ and the slope angle of $34^{\circ}$. Filling of experimental materials was executed in strict accordance with Table 5.

The main goal of this experiment was to simulate the analysis of deformation of rock-soil mass in different directions during dump heaped load and rainfall in the dump of the open-pit mine. Therefore, the laying of optical fibers becomes increasingly more important during the experiment. The three-dimensional schematic diagram of the laying of optical fibers is in Figure 4 ( $X$ direction is the slope's inclination direction, $Y$ direction is the slope direction, and $Z$ direction is the slope settlement direction). There were two layers in the $X$ direction with six sensing optical fibers in each layer. Upper layers (Layer X1) were numbered as $\mathrm{X} 11, \mathrm{X} 12, \mathrm{X} 13, \mathrm{X} 14, \mathrm{X} 15$, and X16 with the linear length of the monitoring optical fiber of $67 \mathrm{~cm}$, and lower layers (Layer X2) were numbered as X21, X22, X23, X24, X25, and X26 with the linear length of the monitoring optical fiber of $108 \mathrm{~cm}$. There were two layers in the $Y$ direction with two sensing optical fibers in each layer. Upper layers were numbered as Y11 and Y12, and lower layers were numbered as Y 21 and Y22 with the linear length of the monitoring optical fiber of $200 \mathrm{~cm}$. Four sensing optical fibers were arranged in the $Z$ direction and were numbered as $\mathrm{Z1}, \mathrm{Z} 2$,
$\mathrm{Z3}$, and Z4 with the linear length of the monitoring optical fiber of $170 \mathrm{~cm}$.

The spacing of each sensing optical fiber is shown in Figure 5 . The spacing between optical fibers at the same level in the $X$ layer was $360 \mathrm{~mm}$, and the spacing between the optical fibers near the model boundary and the model boundary was $10 \mathrm{~mm}$. The vertical distance between optical fibers in the $\mathrm{X} 1$ layer and the X2 layer was $220 \mathrm{~mm}$. The horizontal distance between the Y11, Y12, and Y21 layers and the Y22 layer was $110 \mathrm{~mm}$. The vertical distance between the Y1 layer and the Y2 layer was $220 \mathrm{~mm}$. Z1 and Z2 were located $670 \mathrm{~mm}$ from the bottom of the slope and located at the point of trisection of the model in the $Y$ direction. $\mathrm{Z} 3$ and $\mathrm{Z} 4$ and $\mathrm{Z} 1$ and $\mathrm{Z} 2$ were symmetrically distributed, and the horizontal distance between two sets of optical fibers was $426 \mathrm{~mm}$. Parameters of the optical fiber strain analyzer are shown in Table 6.

Among many factors affecting the stability of the dump in the open-pit mine, heaped load and rainfall are the two most important factors. This experiment was divided into two sections to simulate the impact of different heaped loads and rainfall amounts on the deformation of the slope. Dumping in Dump II of Nanfen Open-Pit Iron Mine is divided into two ways-autodumping and dumping with a crawler-type rock-dumping machine. The heaped load process during the model experiment was mainly divided into two subsections according to the dumping features of the dump. The first subsection of the heaped load process mainly simulated the impact of autodumping on the deformation of the slope, and two passageways of rock dumping were set up at the point of trisection at the top of the slope to loads $20 \mathrm{~kg}, 50 \mathrm{~kg}$, and $70 \mathrm{~kg}$. When the rock-soil mass stabilized, the amount of deformation of each sensing optical fiber was calculated.

The second subsection of the heaped load process simulated the impact of dumping by the crawler-type rockdumping machine on the deformation of the slope, and four passageways of rock dumping were set up at the point of quinquesection at the top of the slope to calculate the amount of deformation of each sensing optical fiber under the conditions of $100 \mathrm{~kg}$ and $140 \mathrm{~kg}$. The impact of different rainfall conditions on the slope deformation was simulated when the heaped load stabilized. The rainfall time required to reach the local daily maximum precipitation was calculated as $5.5 \mathrm{~h}$ (Formula 4) according to hydrogeological conditions in the Nanfen Open-Pit Iron Mine. This experiment used $5.5 \mathrm{~h}$ of rainfall for three consecutive days and compared and analyzed the amount of deformation of each sensing optical fiber so as to obtain the impact of different amounts of rainfall on the slope deformation of the dump.

According to the schematic diagram of the indoor physical model test, a $2 \mathrm{~m} * 2 \mathrm{~m} * 1 \mathrm{~m}$ single-stage dump experimental model was created on-site and reinforced by various materials. The layout line of the fiber optics was designed according to the model size and characteristics of the optical fibers. As the experiment mainly performed deformation of the dump under different loading and rainfall conditions through fiber optic monitoring, the optical fibers were arranged horizontally, longitudinally, and vertically to compare and capture 


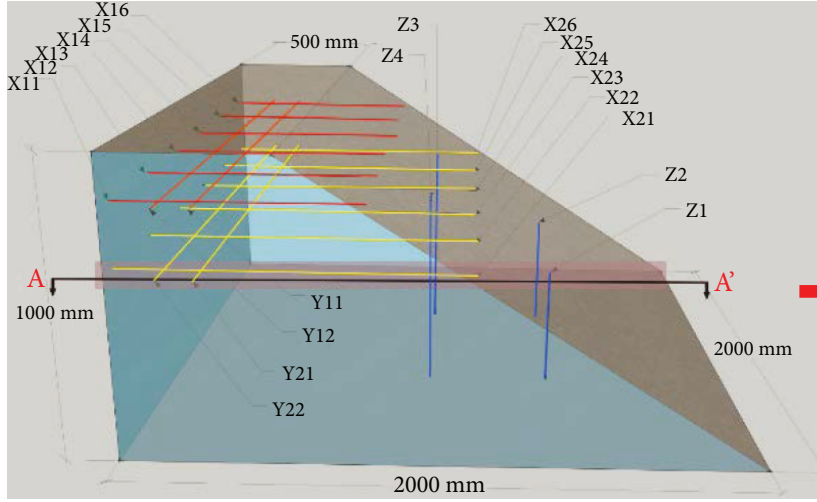

(a)

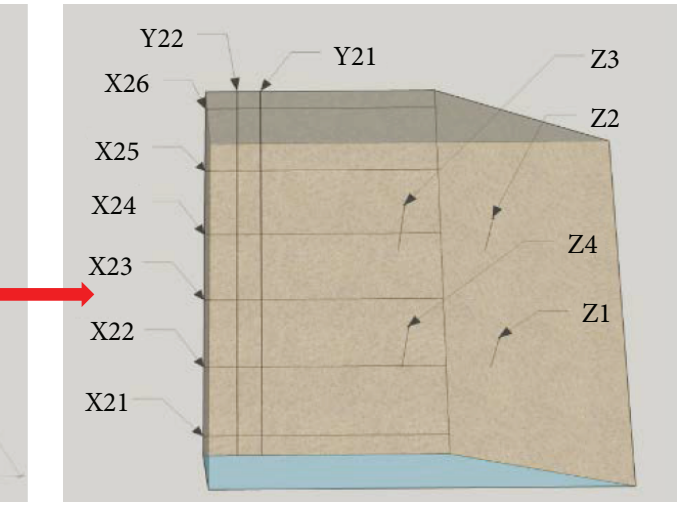

(b)

FIgURE 4: Three-dimensional plan for the laying of sensing optical fibers. (a) Three-dimensional schematic diagram. (b) A-A' cross-section drawing.

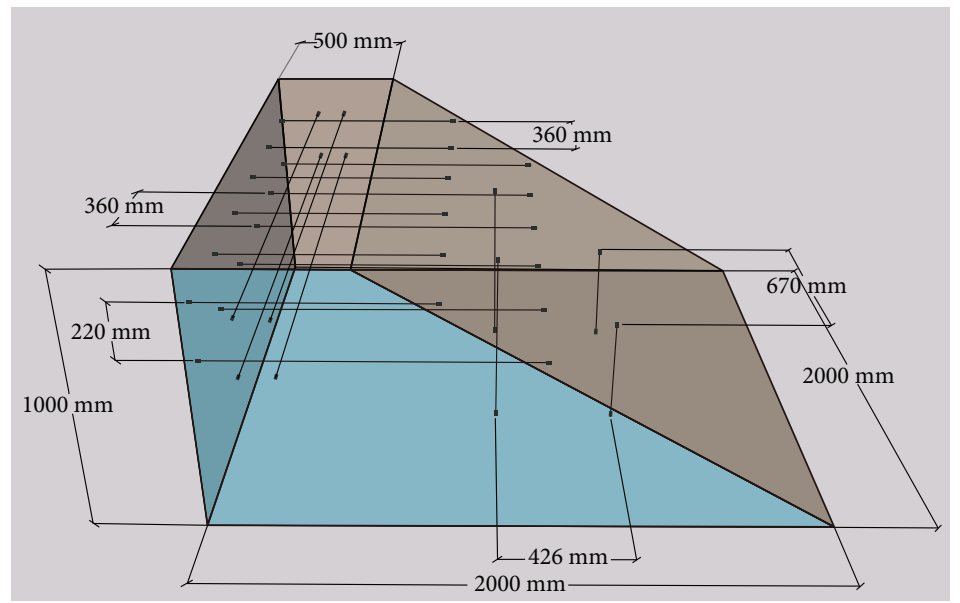

FIgURE 5: Three-dimensional plan of the distribution spacing of optical fibers.

TABLE 6: Parameter settings of the optical fiber strain analyzer.

\begin{tabular}{lcccccc}
\hline $\begin{array}{l}\text { Measurement range } \\
(\mathrm{m})\end{array}$ & $\begin{array}{c}\text { Sampling interval } \\
(\mathrm{m})\end{array}$ & $\begin{array}{c}\text { Pulse width } \\
(\mathrm{ns})\end{array}$ & $\begin{array}{c}\text { Average } \\
\text { time }\end{array}$ & $\begin{array}{c}\text { Starting frequency } \\
(\mathrm{GHz})\end{array}$ & $\begin{array}{c}\text { Scan interval } \\
(\mathrm{MHz})\end{array}$ & $\begin{array}{c}\text { Stop frequency } \\
(\mathrm{GHz})\end{array}$ \\
\hline 100 & 0.05 & 10 & $2^{\wedge} 16$ & 10.700 & 5 & 12.195 \\
\hline
\end{tabular}

the location and size of deformation throughout the dump. The location of each optical fiber was indicated in the model in advance for the analysis of experimental data at a later period. Performing indoor matching according to the calculated content of each grade in the indoor experiment, experimental materials were blended according to set matching, optical fibers and fill material were laid layer by layer, and then laid optical fibers were welded to form the distributed monitoring network, as shown in Figure 6.

\subsubsection{Analysis of Fiber Optic Strain under Different Loading} Conditions. To survey the deformation of each optical fiber under loading conditions of $20 \mathrm{~kg}, 50 \mathrm{~kg}, 70 \mathrm{~kg}, 100 \mathrm{~kg}$, and
$140 \mathrm{~kg}$, the amount of deformation of optical fibers was first surveyed before surcharging to obtain a background load. Then, each load of $20 \mathrm{~kg}, 50 \mathrm{~kg}$, and $70 \mathrm{~kg}$ was individually and in sequence applied at the point of trisection at the edge of the slope top of the dump model, and the deformation of optical fibers was surveyed when the surcharge stabilized. Next, a load of $100 \mathrm{~kg}$ and $140 \mathrm{~kg}$ was applied at the point of quinquesection of the dump, and the deformation of each optical fiber was surveyed when the surcharge stabilized. The experimental process is shown in Figure 7. As the rock-soil mass materials were homogeneous, the symmetrical nature of the system indicates that the strain of the X11 optical fiber would be the same as the X16 optical fiber, the strain of the 


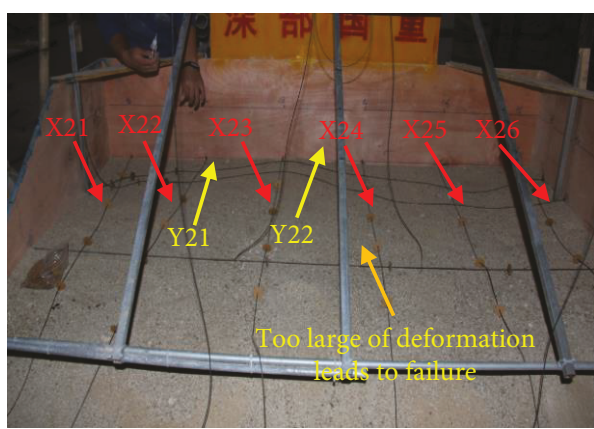

(a)

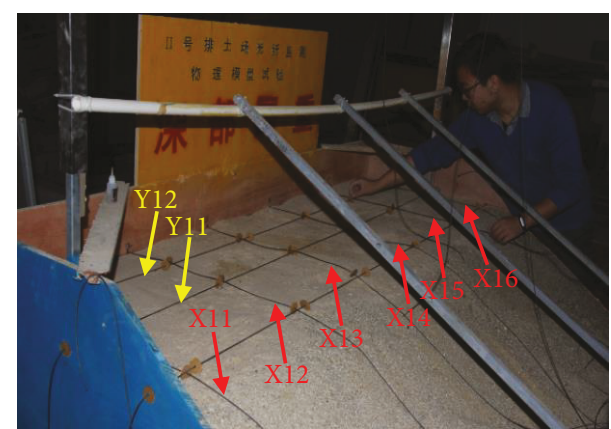

(b)

Figure 6: Laying and welding of optical fibers. (a) Laying of optical fibers in the lower layer. (b) Laying of optical fibers in the upper layer.
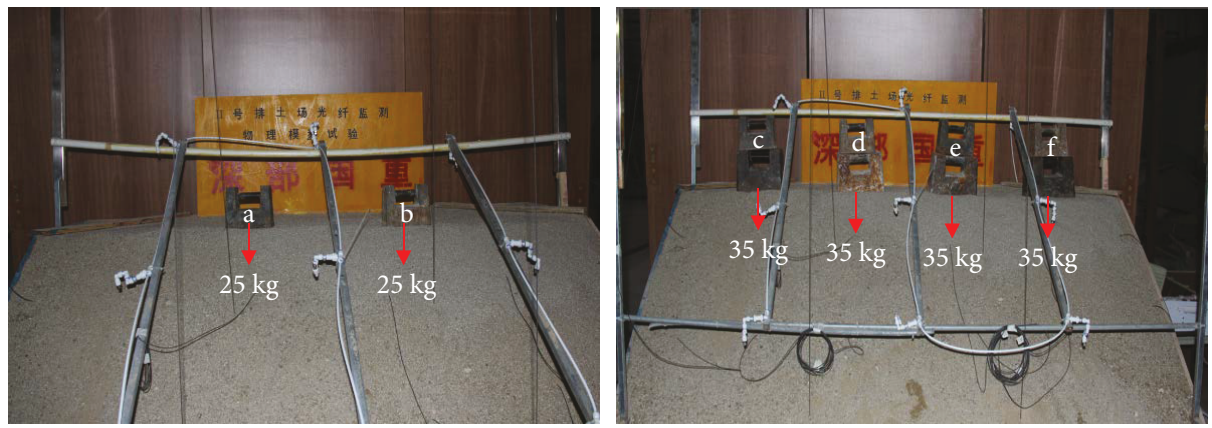

FiguRE 7: Fiber optic strain experiment under different loading conditions.

X12 optical fiber would be the same as the X15 optical fiber, the strain of the X13 optical fiber would be the same as the X14 optical fiber, the strain of the X17 optical fiber would be the same as the X22 optical fiber, the strain of the X18 optical fiber would be the same as the X21optical fiber, the strain of the X19 optical fiber would be the same as the X20 optical fiber, the strain of the Z1 optical fiber would be the same as the Z2 optical fiber, and the strain of the Z3 optical fiber would be the same as the Z4 optical fiber. In actuality, the measured strain trend was consistent with the theoretical value, although differences did exist.

(1) Analysis of Optical Fiber Strain in the X Direction. Using the applied loads and the optical fibers to measure deformation within the rock-soil mass, positive values of the two indicate tension while negative values indicate pressure. Settings of various parameters of BOTDA in the experiment are shown in Table 6. Fiber optic data of each experiment was synthesized: the measured value was subtracted from the initial value to obtain the corresponding strain value and corresponding location data of each optical fiber to the fiber optic sensing network was intercepted to draw the strain network planning, which are shown in Figure 8.

With a constant increase in the load, the overall tensile strain of the optical fibers also gradually increased, and the amount of settlement and slippage in different locations of the dump also correspondingly increased (Figure 8). Deformation of optical fibers in the X1 layer was more obvious (Figure $8(\mathrm{a})$ ) and located just below the location of the applied load. The strain in the center of the optical fibers was more prominent, and the strain of the $\mathrm{X} 12, \mathrm{X} 13$, and X14 optical fibers extended about $3000 \mu \varepsilon$ from the sensor, which was gradually reduced and tended to stabilize from the maximum strain along the direction of laying of the optical fibers. Compared to Figure 8(b), the overall change in the optical fibers in the X2 layer was quite obvious. Optical fiber strain in different positions increased as load increased; however, as the distance of the position of the optical fibers in the $\mathrm{X} 2$ layer from the slope top increased from the top relative to the optical fibers in the X1 layer, they were less affected by the load application position. Therefore, no obvious sudden change in the strain occurred.

(2) Analysis of Optical Fiber Strain in the Y Direction. Loads were applied at the points of trisection and quinquesection near the slope edge at the top of the slope of the indoor dump model. The loads applied at the trisection point were $20 \mathrm{~kg}, 50 \mathrm{~kg}$, and $70 \mathrm{~kg}$ and $100 \mathrm{~kg}$ and $140 \mathrm{~kg}$ at the point of quinquesection. Because the impact of the trisection load on the optical fiber strain was quite different from that of the quinquesection loading in the direction of $Y$, the strain of optical fibers in the $Y$ direction loaded at the point of trisection and the point of quinquesection is shown separately in Figure 9.

Figure 9 shows that the strain of optical fibers synchronously occurred with the deformation of the rock-soil mass of the dump, and the uneven settlement of the rock-soil mass occurred where the load was applied. When the optical fiber 

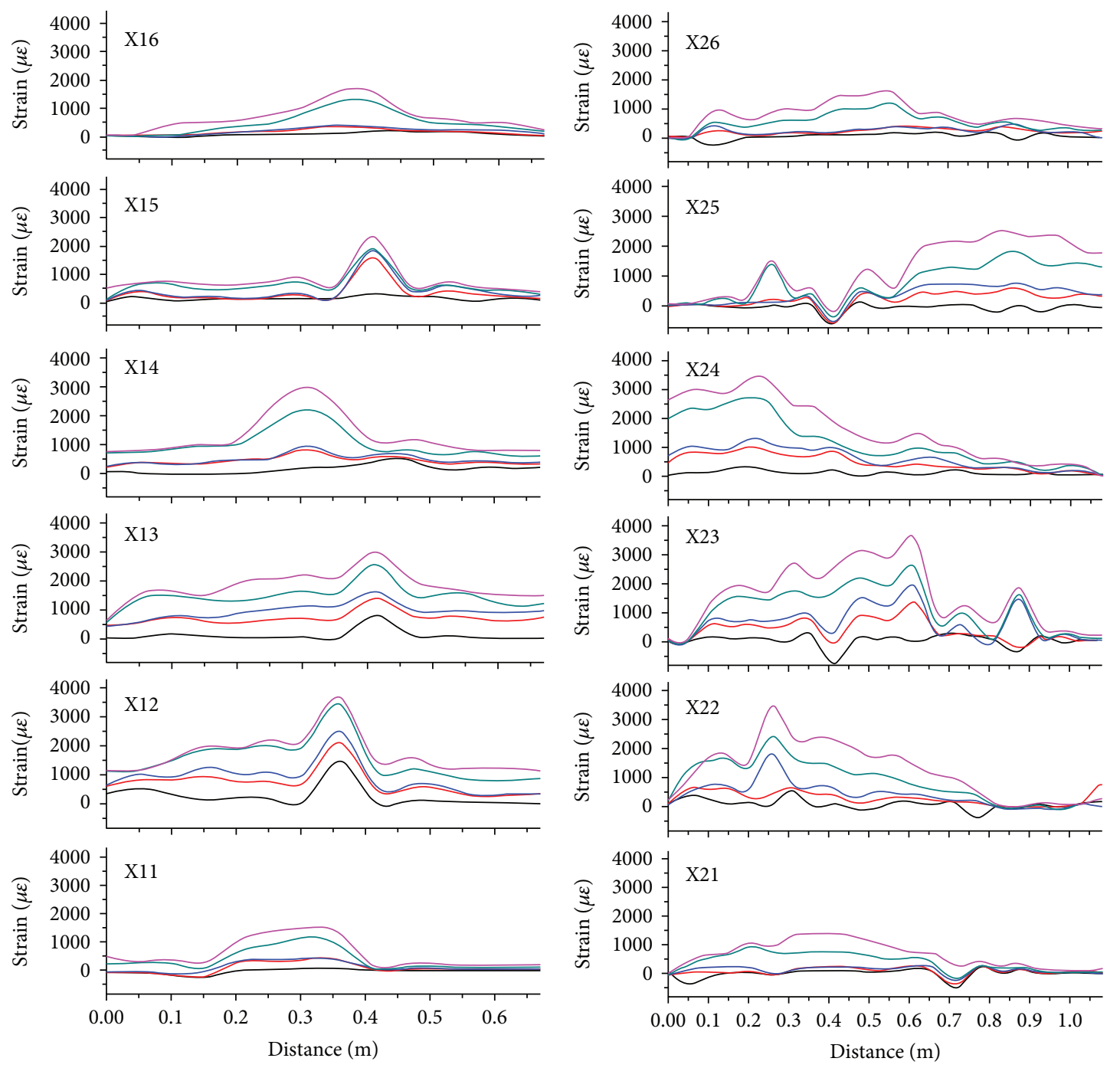

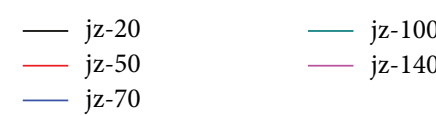

(a)

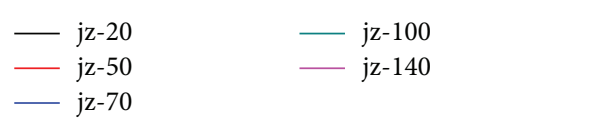

(b)

FiguRE 8: Strain diagram of optical fibers in the $X$ direction under different loading conditions. (a, b) Strain diagram of upper and bottom optical fibers, respectively, in the $X$ direction under different loading conditions.

is in a state of tension, the strain is positive. As the rock-soil mass in the entire dump can be regarded as a plastic body, the rock-soil mass will be squeezed in between the two applied loads. When the optical fiber is under pressure, the strain is negative. By comparing Figures 9(a) and 9(b), when threelevel loads were applied to the dump, the maximum strains of the Y11, Y12, Y21, and Y22 optical fibers were $2060 \mu \varepsilon$, $279 \mu \varepsilon, 615 \mu \varepsilon$, and $229 \mu \varepsilon$, respectively. When two-level loads were applied to the dump, the maximum strains of the Y11, Y12, Y21 and Y22 optical fibers were $2223 \mu \varepsilon$, $409 \mu \varepsilon, 689 \mu \varepsilon$, and $287 \mu \varepsilon$, respectively. Experimental results show that a greater amount of deformation leads to the rocksoil mass being closer to the load application position in different directions. As the distance increased, the load had less influence on the deformation of the rock-soil mass.
(3) Optical Fiber Strain Analysis in the Z Direction. Z1, Z2, $\mathrm{Z} 3$, and Z4 optical fibers were laid from the bottom to the top of the slope vertically, where $\mathrm{Z} 1$ and $\mathrm{Z} 2$ were arranged symmetrically in the $Y$ direction at the point of trisection, $67 \mathrm{~cm}$ from the slope foot, and Z3 and Z4 were arranged symmetrically in the $Y$ direction at the point of trisection, $134 \mathrm{~m}$ from the slope foot. After applying loads of $20 \mathrm{~kg}, 50 \mathrm{~kg}$, $70 \mathrm{~kg}, 100 \mathrm{~kg}$, and $140 \mathrm{~kg}$ to the model, the strain on the optical fibers was tested in the $Z$ direction to further determine settling of the dump more intuitively. Optical fiber strain in the $Z$ direction is shown in Figure 10 .

As the heaped load increased, the tensile strain of the optical fibers also correspondingly increased, indicating that settling of the dump model gradually increased with the increase in load. When the heaped load increased from 

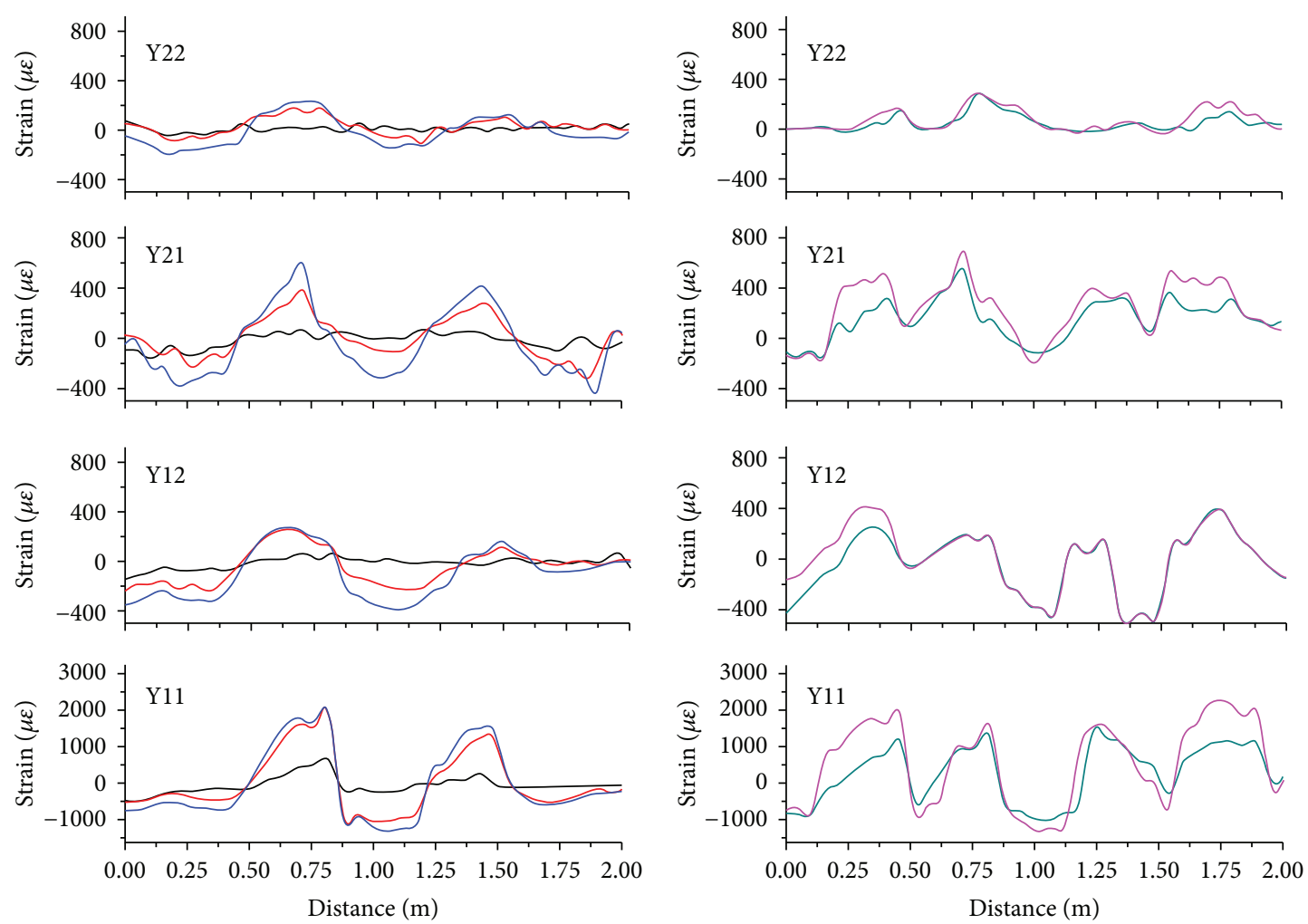

$-\mathrm{jz}-20$
$-\mathrm{jz}-50$
$-\mathrm{jz}-70$

- jz-100

(a) Optical fiber strain diagram in the $Y$ direction under three-level loading conditions

(b) Optical fiber strain diagram in the $Y$ direction under two-level loading conditions

Figure 9: Strain diagram of optical fibers in the $Y$ direction under different loading conditions.
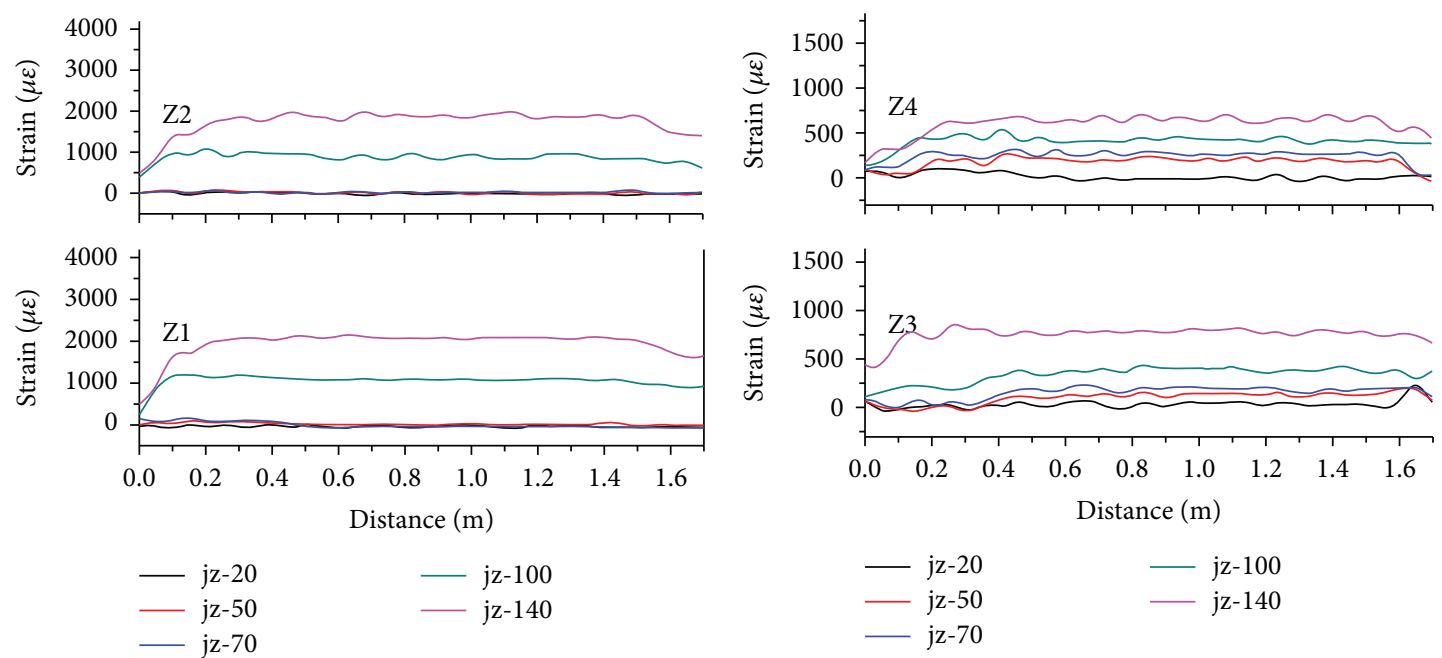

(a) Strain diagram of optical fibers near the bottom of the slope in the direction of $Z$

$$
\begin{array}{rr}
-\mathrm{jz}-20 & -\mathrm{jz}-100 \\
-\mathrm{jz}-50 & \mathrm{jz}-140
\end{array}
$$

(b) Strain diagram of optical fibers near the top of the slope in the direction of $Z$

FIGURE 10: Strain diagram of optical fibers in the $Z$ direction under different loading conditions.

$20 \mathrm{~kg}$ to $70 \mathrm{~kg}$, the relative strain increment of each optical fiber in the $Z$ direction was not very obvious. As the heaped load continued to increase, the relative strain increment of optical fibers gradually increased, and when the heaped load reached $140 \mathrm{~kg}$, the relative settlement increment of the dump model reached its maximum value. 

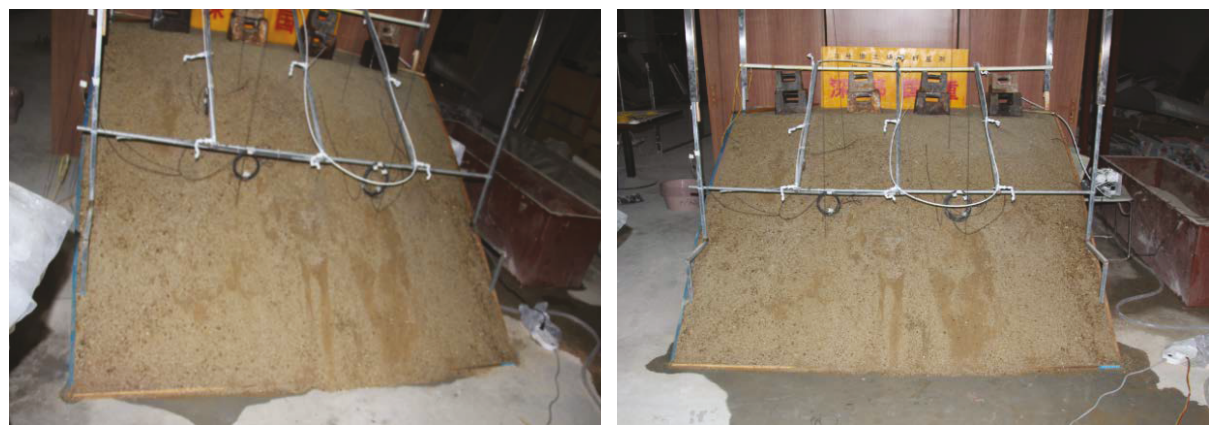

FIGURE 11: Fiber optic strain experiment under different rainfall conditions.

3.2.4. Analysis of Fiber Optic Strain under Different Rainfall Conditions. To determine the effects of rainfall on the stability of a dump, it "rained" for 5, 10, and 15 hours with a rainfall device. The strain of each optical fiber under different rainfall conditions was then determined. The experimental process is shown in Figure 11.

(1) Analysis of Optical Fiber Strain in the X Direction under Different Rainfall Conditions. Comparative analysis was performed for the six optical fibers' strains in layers X1 and $\mathrm{X} 2$ on days one through three (Figure 12).

The strain of the sensing optical fibers was greatest with the rainfall on the first day, decreasing on the second day, and was least on the third day. On the first day of rainfall, a sudden change in the strain of each optical fiber occurred at various positions throughout the model (Table 7). The overall strain trend and positions of sudden change of the X11 optical fiber was essentially consistent with that of the X16 optical fiber, along with X12 and X15 and X13 and X14. This is consistent with the symmetrical arrangement of sensing optical fibers in the experimental model.

It can be seen from six optical fibers in the X2 layer that the sensing optical fiber strain shows the same variation trend as that in the X1 layer. Also same as X1, X2 had a sudden change in strain at various positions throughout the model with the first day of rainfall (Table 7). As the plane distance from the X2 layer to the load application position was large, the overall strain of the sensing optical fibers was much smaller than that of the optical fibers in the X1 layer.

Using X13 and X23 sensing optical fibers for comparative analysis of strain during each day of rainfall, there was a very obvious trend of the strain endured by the optical fibers over the course of the three days of rainfall. On the first day of rainfall, the strain was relatively large, reaching $2560 \mu \varepsilon$. On the second and third days of rainfall, the strain decreased and tended to stabilize along the direction of the length of the optical fiber. This occurred because loose particles of the rock-soil mass before rainfall have high porosity, are filled mostly with air rather than liquids, and are able to be highly compressed. With the rainfall on the first day, the rock-soil mass is washed out by rainwater, and the flow of pore water drives the deformation of the rock-soil mass; it also becomes gradually saturated. The strain in the positions $0.36 \mathrm{~m}$ from the X13 optical fiber and $0.63 \mathrm{~m}$ from the X23 optical fiber suddenly increased on the first day because the amount of deformation of the rock-soil mass suddenly increased in this position due to movement of particles caused by the increased water in the dump. More attention is provided to the generation of a potential sliding surface in the follow-up analysis. At the end of the rainfall on the first day, the rocksoil mass started to consolidate and settle, becoming denser and less compressible. The impact of rainfall on the second and third days on the amount of deformation of optical fibers becomes increasingly smaller with the passage of time, indicating that the overall rock-soil mass was in a relatively stable state with relatively small amount of deformation.

(2) Analysis of Optical Fiber Strain in the Y Direction under Different Rainfall Conditions. As shown in Figure 13, optical fibers in the $Y$ direction had a similar trend as those in the $X$ direction. As the layout of optical fibers in the $Y$ direction was parallel to the slope, the two positions of sudden change in the strain appeared along the length of the optical fibers. Positions with sudden change in strain were distributed symmetrically along the midpoint of the optical fibers; however, the overall trend of the Y22 optical fiber was relatively stable, without obvious strain with a sudden change. This is mostly due to the locations of the Y22 optical fiber. The Y22 optical fiber was far from the sliding direction of the rock-soil mass and close to the back of the model; the model had a great resistance to deformation in this place. The overall strain at this location was relatively small, and the strain along the direction of optical fibers was relatively stable. Optical fibers in both the upper and lower layers in the directions of $X$ and $Y$ were all in this same plane. Comparing Figures 12 and 13, the strain trends of the strain diagrams of optical fibers in each layer in the directions of $X$ and $Y$ were the same.

(3) Analysis of Optical Fiber Strain in the Z Direction under Different Rainfall Conditions. It can be seen from the strain diagram of the four optical fibers in the $Z$ direction that the strain of Z1 was similar to that of Z2, as was Z3 and Z4 (Figure 14). All positions of optical fibers with a sudden change in strain appeared at the boundary of optical fibers and slope, which is shown in Figure 15. However, the overall strain was relatively small, and positions with sudden change and strain are shown in Table 7.

3.3. Potential Sliding Surface Judgments. Table 7 summarizes the sudden change in the strain of each optical fiber during 

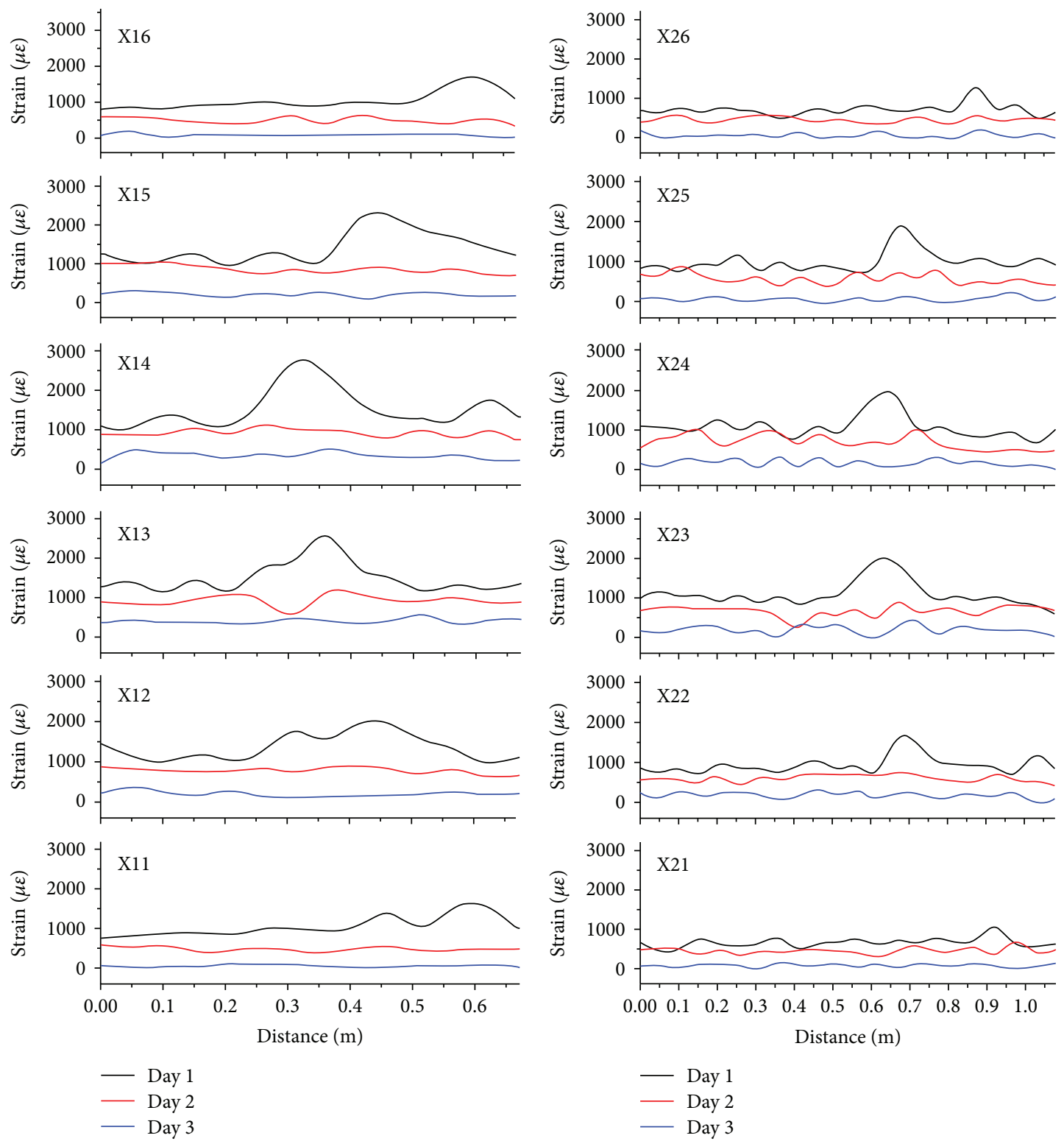

(a) Comprehensive strain diagram of upper optical fibers in the $X$ direction with three days of rainfall

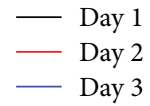

(b) Comprehensive strain diagram of bottom optical fibers in the $X$ direction with three days of rainfall

Figure 12: Comprehensive strain diagram of optical fibers in the $X$ direction with three days of rainfall.

rainfall on the first day. Strain increments at varying degrees appeared in each optical fiber during rainfall on the first day, and due to the symmetrical distribution of sensing optical fibers, strain of each optical fiber had symmetrical growth. These sudden changes in strain indicate new deformation at these locations, and the location of the most dangerous sliding surface was obtained from a comprehensive analysis of the strain of each optical fiber.

Based on the slope failure mechanisms and the geometrical characteristics of a sliding surface, the most common types of landslides that occurred during testing are classified as four types: plane slide failure, circular slide failure, wedge slide shape failure, and compound slide failure. The sudden change in the strain of each optical fiber shows that slow trace deformation had already begun inside the dump, accompanied by shear failure due to partial tension and continuously decreased strength of the slope. However, no actual landslide had yet occurred. The sudden change in the strain of each sensing optical fiber during rainfall on the second and third days indicates that with the increase of rainfall time, the sliding surface gradually extended deeper into the slope, and finally, the sliding surface was completely linked. The process creating the sliding surface is shown in Figure 16. However, as rainfall stopped, the rock-soil mass of the dump consolidated and settled, and the entire dump stabilized.

Coordinates of positions with sudden change in the strain in the three-dimensional schematic diagram of the indoor 
TABLE 7: Corresponding data of the strain of each optical fiber.

\begin{tabular}{|c|c|c|c|c|}
\hline Fiber no. & Fiber length (m) & $\begin{array}{l}\text { Position with sudden change } \\
\text { in the strain }(\mathrm{m})\end{array}$ & $\begin{array}{l}\text { Strain in the place with } \\
\text { sudden change }(\mu \varepsilon)\end{array}$ & Strain increment $(\mu \varepsilon)$ \\
\hline $\mathrm{X} 11$ & 0.667 & 0.59 & 1624 & 571 \\
\hline $\mathrm{X} 12$ & 0.667 & 0.43 & 2028 & 917 \\
\hline $\mathrm{X} 13$ & 0.667 & 0.36 & 2558 & 1236 \\
\hline $\mathrm{X} 14$ & 0.667 & 0.32 & 2777 & 1497 \\
\hline $\mathrm{X} 15$ & 0.667 & 0.44 & 2323 & 1170 \\
\hline $\mathrm{X} 16$ & 0.667 & 0.61 & 1708 & 731 \\
\hline $\mathrm{X} 21$ & 1.078 & 0.92 & 1042 & 346 \\
\hline $\mathrm{X} 22$ & 1.078 & 0.69 & 1675 & 721 \\
\hline $\mathrm{X} 23$ & 1.078 & 0.63 & 1991 & 971 \\
\hline $\mathrm{X} 24$ & 1.078 & 0.64 & 1969 & 912 \\
\hline $\mathrm{X} 25$ & 1.078 & 0.67 & 1910 & 952 \\
\hline $\mathrm{X} 26$ & 1.078 & 0.87 & 1292 & 552 \\
\hline Y11 & 2.0 & $0.21 / 1.75$ & $2066 / 2195$ & $892 / 994$ \\
\hline Y12 & 2.0 & $0.82 / 1.27$ & $1772 / 1698$ & $892 / 690$ \\
\hline $\mathrm{Y} 21$ & 2.0 & $0.81 / 1.20$ & $1541 / 1321$ & $661 / 424$ \\
\hline $\mathrm{Y} 21$ & 2.0 & - & - & - \\
\hline $\mathrm{Z} 1$ & 1.694 & 0.46 & 695 & 309 \\
\hline $\mathrm{Z} 2$ & 1.694 & 0.43 & 709 & 314 \\
\hline $\mathrm{Z3}$ & 1.694 & 0.85 & 885 & 338 \\
\hline $\mathrm{Z} 4$ & 1.694 & 0.87 & 896 & 357 \\
\hline
\end{tabular}
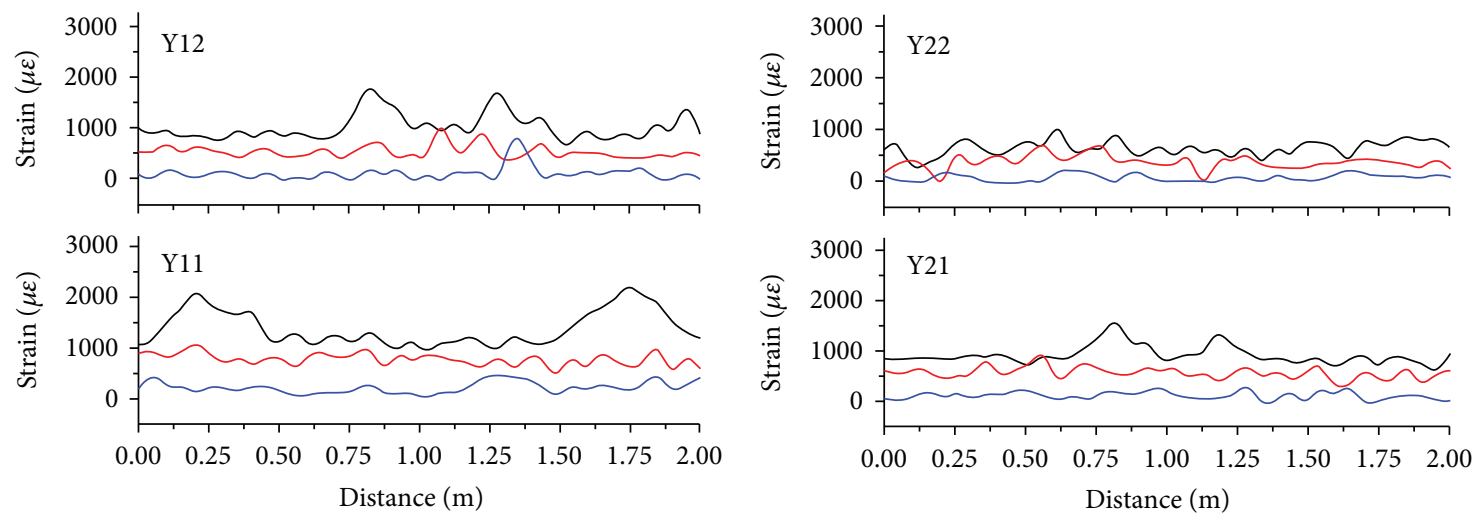

- Day 1
- Day 2
- Day 3

(a) Comprehensive strain diagram of upper optical fibers in the $Y$ direction with three days of rainfall

$$
\begin{array}{r}
\text { - Day } 1 \\
\text { - Day } 2 \\
\text { - Day } 3
\end{array}
$$

(b) Comprehensive strain diagram of lower optical fibers in the $Y$ direction with three days of rainfall

Figure 13: Comprehensive strain diagram of optical fibers in the $Y$ direction with three days of rainfall.

physical model experiment were connected (Figure 17). The slope was in an extremely unstable state during rainfall on the first day, and a dangerous circular sliding surface formed (blue).

Figure 18 shows the porosity within the particles of rock-soil materials used by the experiment observed through 50x magnification by SEM before and after rainfall. The porosity before rainfall was significantly less than that after rainfall because the materials that comprised the rock-soil mass were mainly fine sandstone composed of argillaceous cementation. Affected by rainfall, the argillaceous cements were eroded, so that cementation of sandstone particles diminished. During the rainfall, fine particles slid into the pores among the coarse particles and gradually formed small cracks as particles moved. These cracks gradually increased and linked into the dangerous sliding surface. Due to the limited precipitation in the experiment, no actual landslide occurred. 

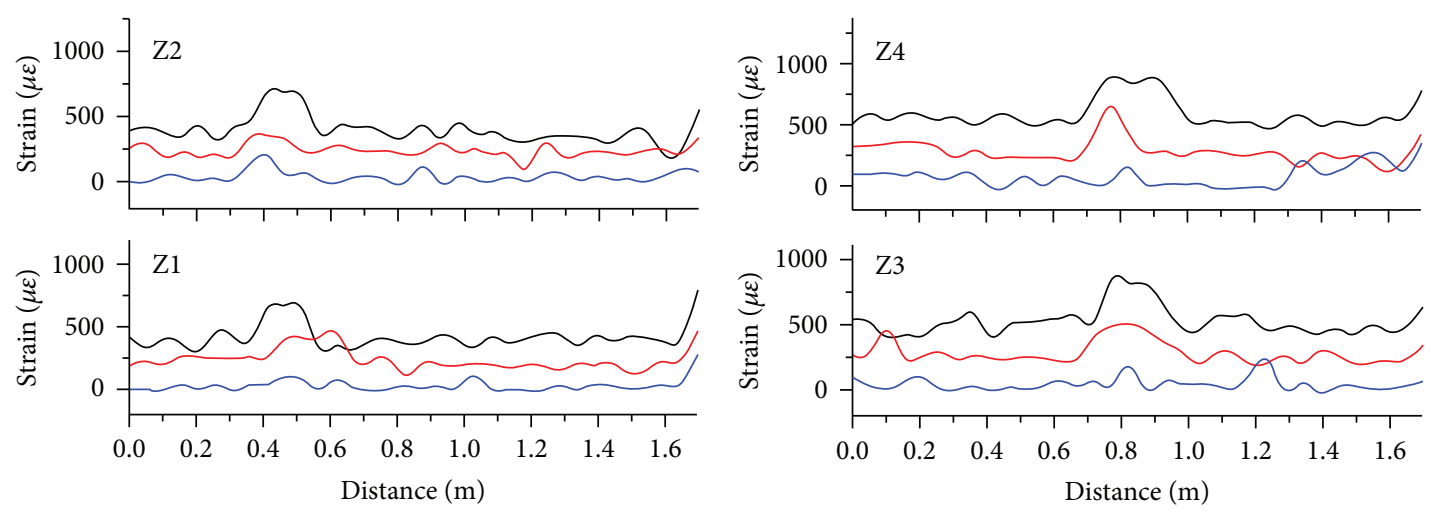

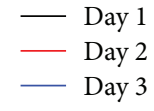

(a) Strain diagram of optical fibers near the bottom of the slope in the $Z$ direction

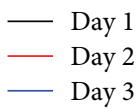

(b) Strain diagram of optical fibers near the top of the slope in the $Z$ direction

FIgURE 14: Comprehensive strain diagram of optical fibers in the $Z$ direction with three days of rainfall.

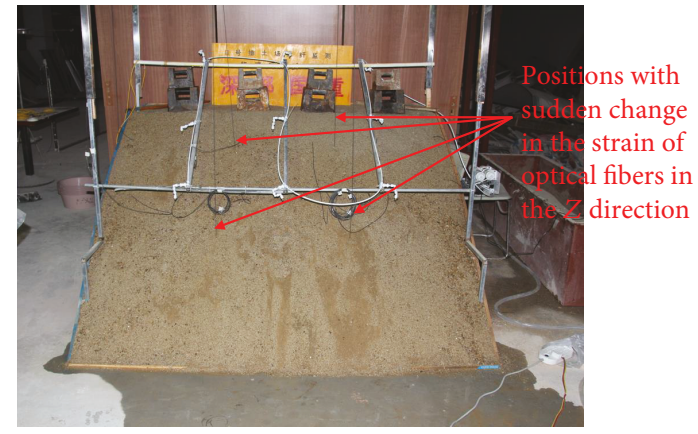

FIgURE 15: Locations of sudden change in the strain of optical fibers in the $Z$ direction.

\section{Numerical Simulation Calculation of the Stability of Dump II}

Combined with physical simulation test parameters, the numerical simulation used FLAC3D software to establish a Mohr-Coulomb constitutive model. The size of the model was the same as that of the indoor physical model $(2 \mathrm{~m} * 2 \mathrm{~m} * 2 \mathrm{~m})$, so that monitoring data of further numerical simulation could be consistent with those of the indoor test. This simulation was mainly performed to create a similar simulation based on the loading process in the contents of the experiment. The loading process was divided into two stages and five working conditions. In the first stage, loads of $20 \mathrm{~kg}, 50 \mathrm{~kg}$, and $70 \mathrm{~kg}$ placed at the trisection at the top of the model were simulated, a total of two points. Simulation used vertical surface stress loading, and according to the contact area of the actual load weight of $240 \mathrm{~m}^{2}$, the vertical compressive stress applied to each working point was $4.46 \mathrm{e} 3 \mathrm{~Pa}, 4.46 \mathrm{e} 3 \mathrm{~Pa}$, and $1.458 \mathrm{e} 4 \mathrm{~Pa}$. In the second stage, loads of $100 \mathrm{~kg}$ and $140 \mathrm{~kg}$ were loaded onto the quinquesection at the top of the model, a total of four points. Simulation also used vertical surface stress loading, and the vertical compressive stress applied to each working point was $1 \mathrm{e} 4 \mathrm{~Pa}$ and $1.458 \mathrm{e} 4 \mathrm{~Pa}$, respectively.

4.1. Parameter Selection and Model Establishment. Numerical parameters were set according to the relevant parameters of the indoor physical simulation test model, which are shown in Table 8.

According to the relevant parameters and loading process, the detailed calculation process was divided into two parts. First, the elastic model was calculated and the stress conditions were generated consistent with the test site. Finally, the elastic-plastic calculation was performed. Figure 19 is the generated elastic stress field.

4.2. Analysis of Numerical Simulation Results under Different Conditions of Heaped Loads. The corresponding calculation results were obtained after numerical simulation of the dump model:

(1) Calculation results of $20 \mathrm{~kg}$ of load: as shown in Figure 20, the maximum value of the vertical displacement was calculated as $0.09 \mathrm{~mm}$ after the model stabilized. In the model, there was a clear difference between the middle and lower stable zone and the upper strain zone. The model was free of damage after the calculation of model stability. However, after the model was loaded, a potential shear strain belt that was linked in its shear stress field was obvious, and the belt passed through a point of loading which was distributed in the shape of an arc

(2) Calculation results of $50 \mathrm{~kg}$ of load: as shown in Figure 21, the maximum value of vertical displacement was calculated as $0.62 \mathrm{~mm}$ after the model stabilized. In the model, there was a clear difference between the middle and lower stable zone and the upper strain zone. The model was free of damage after the calculation of model stability. However, after 


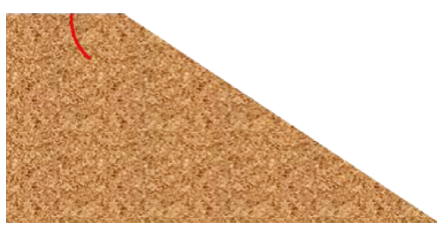

(a) Slope cracking

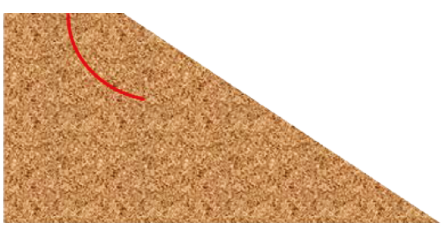

(b) Crack propagation

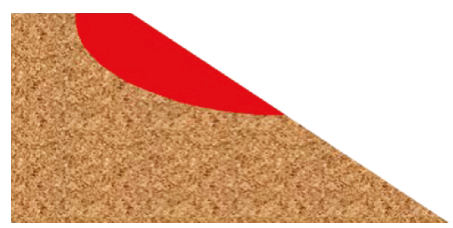

(c) Sliding surface run-through

FIGURE 16: Slope instability process.

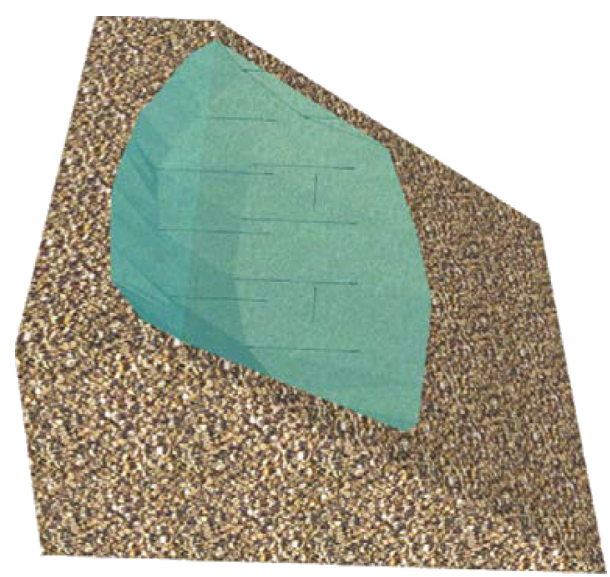

Figure 17: Three-dimensional schematic diagram of the sliding surface.

the model was loaded, the potential shear strain belt that was linked in its shear stress field was obvious, and the belt passed through the point of loading with an arc-shaped distribution

(3) Calculation results of $70 \mathrm{~kg}$ of load: as shown in Figure 22, vertical deformation of the slope was calculated to be $1.2 \mathrm{~mm}$ after the model stabilized (the settlement of the loading point was not included in the maximum value). In the model, there was a clear difference between the middle and lower stable zone and the upper strain zone. The model was free of damage after model stabilization. However, after the model was loaded, model appearance did not show the obvious shear belt in its shear stress field. However, it can be seen from the perspective view that shear strain started at the top point of loading, and wedge deformation occurred around the loading area in this position. In the two points of loading, the arc-shaped surface that was linked in the lower part of the loading point on the right formed, indicating that during the loading process with these working conditions, the damage arc formed from the inside and from the top to bottom

(4) Calculation results of $100 \mathrm{~kg}$ of load: as shown in Figure 23, in the working conditions of calculation, there were four loading points. Similar to the above calculation, the relatively large settlement and shear strain appeared first right at the location of the loading point, and the vertical deformation of the slope was $1.2 \mathrm{~mm}$ after model stabilization, indicating that although the total load was relatively large, due to dispersed positions of loading points, the load too was dispersed. This helped protect slope stability. Similarly, in the shear perspective view of the model, the shear belt that was linked appeared preferentially in the two middle loading points, and an enlarged shear zone occurred in the loading position at the top

(5) Calculation results of $140 \mathrm{~kg}$ of load: as shown in Figure 24, with these working conditions, there were four loading points. Similar to the above calculation, the relatively large settlement and shear strain first appeared right at the location of the loading points, and the vertical deformation of the slope was $4 \mathrm{~mm}$ after model stabilization. Although the locations of the loading points were dispersed, loads were also dispersed to some extent, maintaining slope stability. However, the deformation of the slope was relatively large after this loading and damage appeared, indicating that a large enough load can create an unstable slope after the loading point is arranged. Similarly, in the shear perspective view of the model, the shear belt that was linked appeared preferentially in the two middle loading points, and the enlarged shear zone occurred in the loading position at the top but did not extend to the outside of the model.

In general, numerical analysis results were similar to those of the indoor physical model. As the loading intensity continued to increase, vertical displacement of the slope gradually increased, and the shear stress field in the loading process of two points had an obvious potential shear strain belt that was linked. The damage arc formed from the inside and from the top to bottom. The way of loading changed in the loading process of four points, although the deformation of the slope increased as the load increased, and the slope was eventually damaged when the load reached $140 \mathrm{~kg}$. The linked shear belt preferentially appeared in the two middle loading points, and an enlarged shear zone occurred in the loading position at the top but did not extend to the outside of the model.

\section{Discussion}

The location of the dangerous potential sliding surface was determined through the size of deformation in locations where optical fibers deformed within the indoor physical model. Rainfall and heaped load had a relatively extensive 


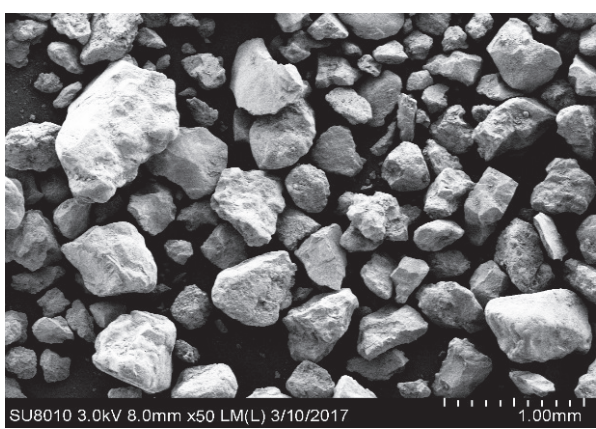

(a) Scanned sample picture before rainfall

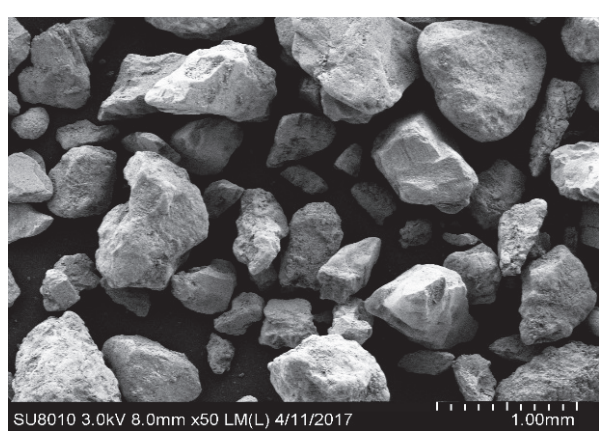

(b) Scanned sample picture after rainfall

FIGURE 18: Sample SEM pictures before and after rainfall.

TABLE 8: Model of physical and mechanical parameters.

\begin{tabular}{lcccccc}
\hline Names of rocks & $\begin{array}{c}\text { Weight } \\
\left(\mathrm{kg} / \mathrm{m}^{3}\right)\end{array}$ & $\begin{array}{c}\text { Modulus of } \\
\text { volume }(\mathrm{MPa})\end{array}$ & $\begin{array}{c}\text { Shear modulus } \\
(\mathrm{MPa})\end{array}$ & Cohesion $(\mathrm{Pa})$ & Friction angle $\left(^{\circ}\right)$ & Tensile strength $(\mathrm{Pa})$ \\
\hline Chlorite amphibolite & 2560 & 70 & 41 & 900 & 21 & 0 \\
\hline
\end{tabular}

FLAC $3 D 5.00$

(C)2012 Itasca Consulting Group Inc.

Step 500

2017/4/21 18:08:43

Contour of ZZ-stress

Calculated by volumetric averaging

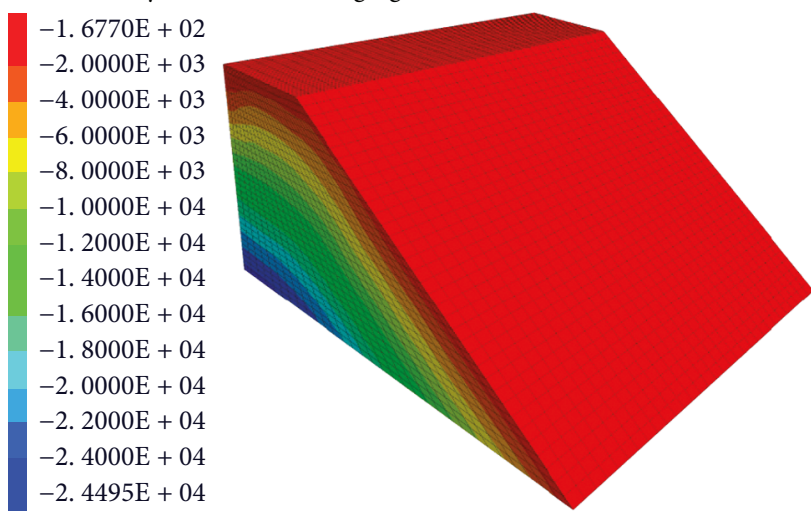

FIgURE 19: Results of the of elastic stress field calculation.

impact on landslides in a dump. With the increase of heaped load, the place between the two heaped load points was squeezed and deformation slowly increased; deformation of the rock-soil mass was obvious at the beginning of rainfall. As the rainfall intensity continued to increase, a dangerous sliding surface was generated. Because the rainfall intensity in the experiments failed to meet the requirements of landslide and mudslide (not enough total amount), no actual landslide ever occurred in these experiments. However, as rainfall stopped, the rock-soil mass of the dump consolidated and settled, and the entire dump tended to stabilize. Compared with other monitoring methods in dumps, fiber optic monitoring can be implemented over long distances and large areas, although it still does have blind spots in its monitoring. This method does not affect the integrity and structural safety of the monitored rock-soil mass and can provide an early warning of landslides and deformation under a dynamic working process of a site, as proven by Naruse et al. [34] and Kogure and Okuda [35]. However, the workload needed for arranging optical fibers is relatively large, and fiber optics are fragile and easily damaged; thus, the fiber optics need to have installed the protective sleeve, which increases monitoring cost.

FLAC3D was adopted to analyze the vertical displacement and shear strain of the dump under different heaped load conditions, which provided the basis for the determination of the position of the sliding surface in the slope. As the loading intensity continued to increase, vertical displacement of the slope gradually increased, and the shear stress field in the two-point loading process showed an obvious linked potential shear strain belt. A damage arc formed from the inside and from top to bottom. The way of loading changed in the four-point loading process, although the deformation of the slope increased as the load increased, and the slope became damaged under a load of $140 \mathrm{~kg}$. There was still the linked shear belt that preferentially appears in the two middle loading points, and an enlarged shear zone occurred at the location of loading at the top that did not extend to the outside of the model. In general, the results of numerical analysis were similar to results of the indoor physical model experiment and provided a theoretical basis for field experiments.

\section{On-Site Experimental Scheme of Fiber Optic Monitoring of Dump II}

Based on the fiber optic monitoring indoor physical model experiments and numerical simulation results of the stability of Dump II, a large deformation on-site monitoring design was implemented according to the status quo of dumping 


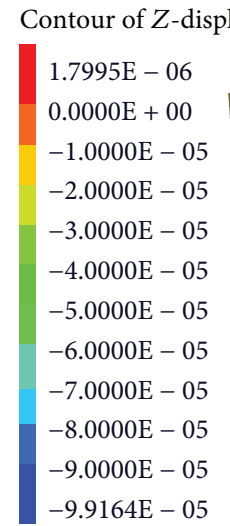

(a) Vertical displacement field
Contour of max. shear strain increment

Calculated by volumetric averaging

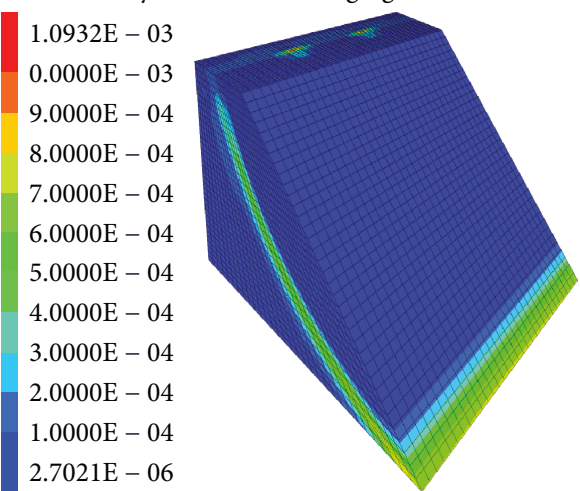

(b) Shear strain field

Figure 20: Vertical displacement field and shear strain field after loading of $20 \mathrm{~kg}$.

Contour of $Z$-displacement

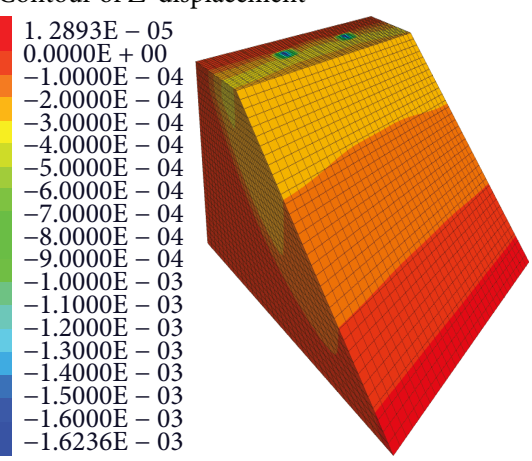

(a) Vertical displacement field
Contour of max. shear strain increment

Calculated by volumetric averaging

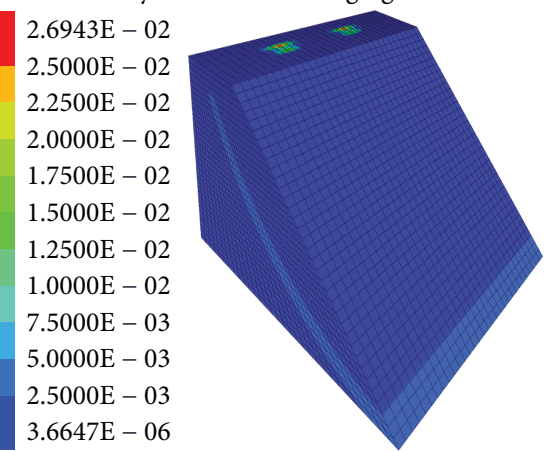

(b) Shear strain field

Figure 21: Vertical displacement field and shear strain field after loading of $50 \mathrm{~kg}$.

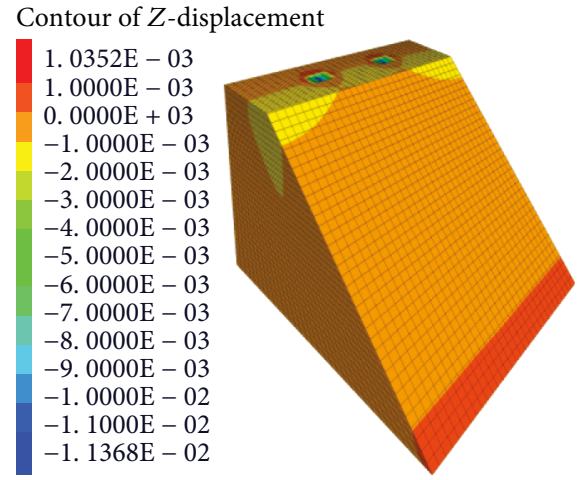

(a) Vertical displacement field
Contour of max. shear strain increment

Calculated by volumetric averaging

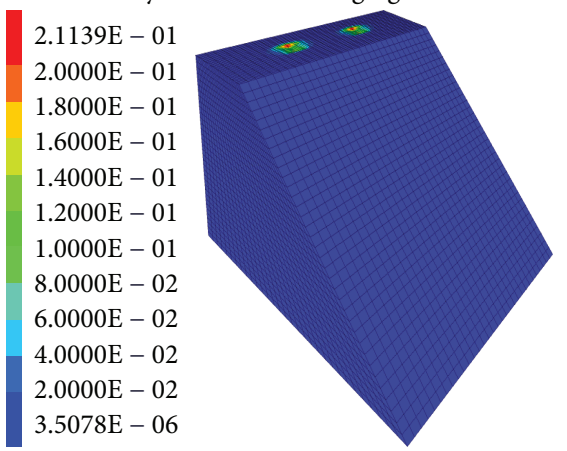

(b) Shear strain field

Figure 22: Vertical displacement field and shear strain field after loading of $70 \mathrm{~kg}$.

within the dump. Different optical cables were selected and laid in different locations throughout the dump. Cables were selected by comparing which were suitable for soil deformation monitoring during the excavation of the slope in the open-pit mine. The lengths of A and B lines were $200 \mathrm{~m}$ each, and each cable was redundant with $20 \mathrm{~m}$ at both ends. The length of each cable was $220 \mathrm{~m}$ (Figure 25). The trench was excavated at the top of the slope where the platform was located, and the distributed sensing cables and fiber optic monitoring pipes were buried into the slope. Soil of the slope 


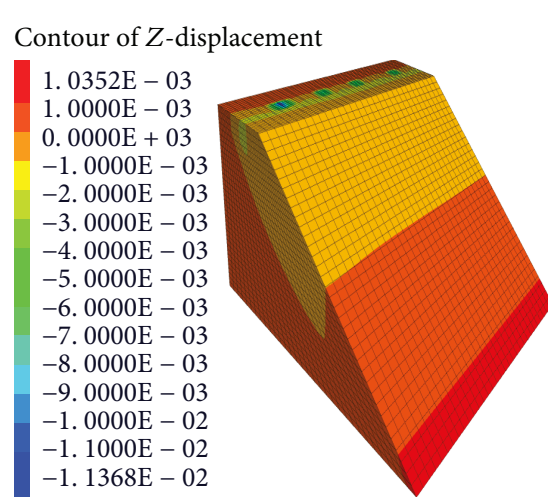

(a) Vertical displacement field

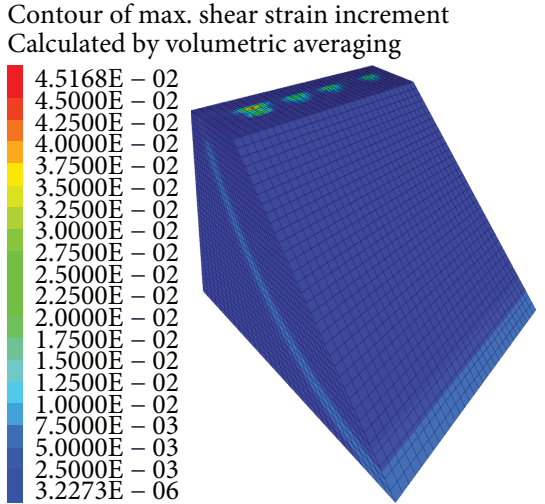

(b) Shear strain field

FIgURE 23: Vertical displacement field and shear strain field after loading $100 \mathrm{~kg}$.

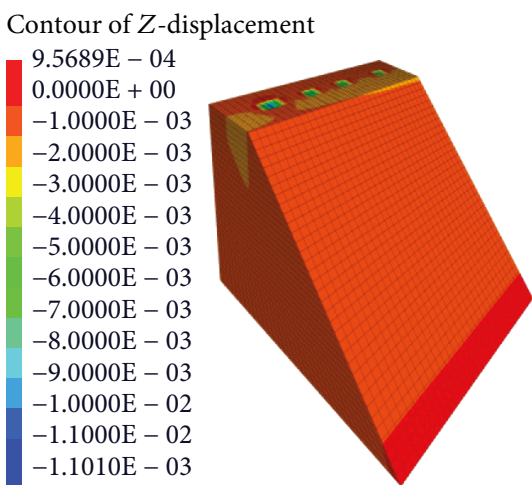

(a) Vertical displacement field
Contour of max. shear strain increment Calculated by volumetric averaging

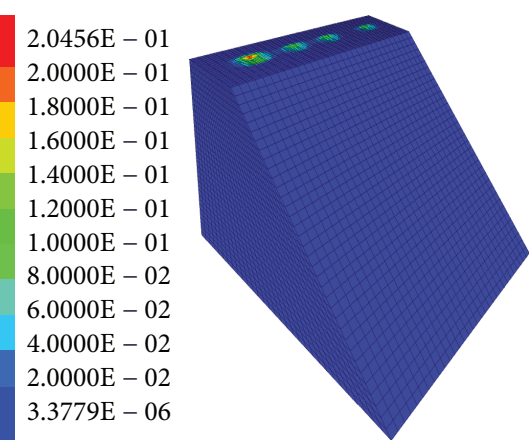

(b) Shear strain field

Figure 24: Vertical displacement field and shear strain field after loading of $140 \mathrm{~kg}$.

slides downward as it is affected by slope dumping and excavation. In the area with soil deformation of the slope, cables deform with the soil, thus causing tensile deformation. A distributed optical fiber strain tester was used to test the amount of optical cable deformation and determine the area of deformation of the slope.

The trench was excavated according to the designed optical fiber monitoring line. The optical fiber sensor was installed in the trench and buried in the backfill soil. Wiring ports at the beginning and end of the monitoring line were reserved in order to be able to measure deformation and strain. The specific layout on site is shown in Figure 26.

Through the excavation test of the dump slope, a scheme for laying optical fibers suitable for the monitoring of Dump II was finally selected, which will also provide a field test for large-scale application of fiber optic monitoring in a dump that will be reported on at a later period. Monitoring and reporting of the fiber optic network will occur at a later date.

\section{Conclusions}

The Dump II (Fengjiadonggou) within the Nanfen Open-Pit Iron Mine was the prototype for determining strain and deformation through experimental study and numerical simulation calculation on fiber optic monitoring with the indoor physical model combined with on-site engineering survey data and landslide analysis methods of the dump. The following conclusions are obtained:

(1) The indoor physical model experiment of fiber optic monitoring of the dump determined the deformation in different positions of the dump under different heaped loads and rainfall amounts. The location of the dangerous potential sliding surface was determined using the size of deformation in locations where optical fibers were deformed. The reasoning for the sliding face was analyzed through theory, although the pore size among particles of the rocksoil mass before and after the experiment was measured using SEM. Rainfall and the heaped loading method have a relatively extensive impact on the occurrence of landslides in a dump

(2) FLAC3D was used to analyze the vertical displacement and shear strain of the dump under different heaped load conditions, which provided the basis for the determination of the position of the sliding 


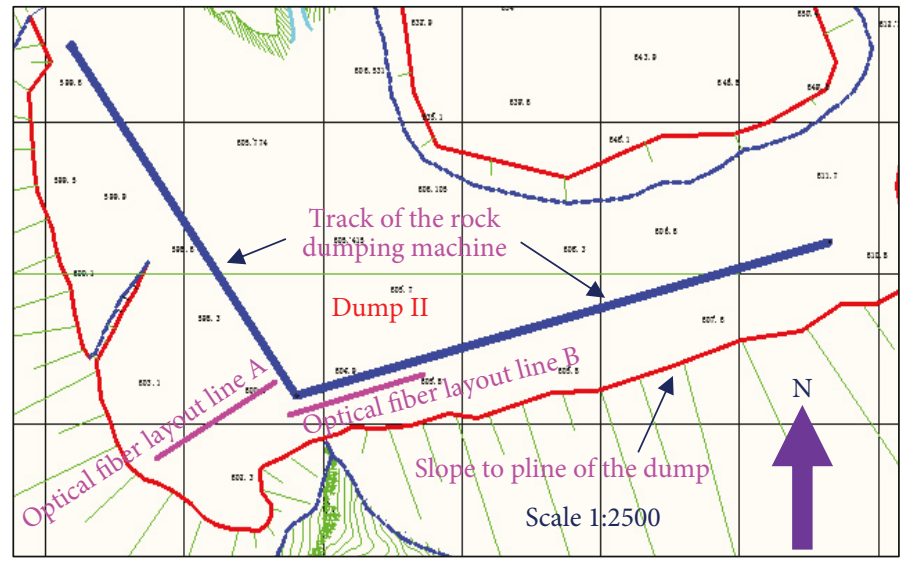

FIgURE 25: Optical fiber layout map of dump deformation monitoring.

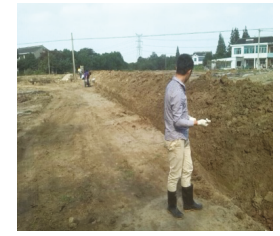

(a) Cable laying

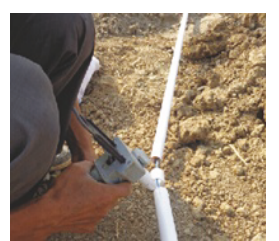

(d) Installation of the protective sleeve at the bent location

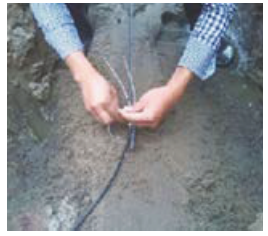

(b) Cable binding

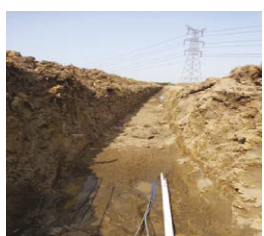

(e) Trench backfilling

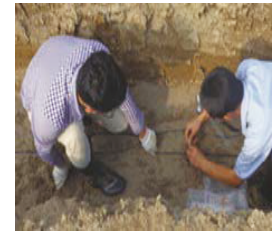

(c) Glue injection fixing

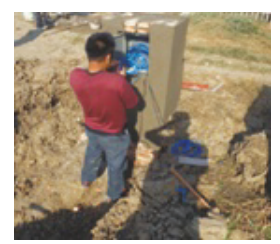

(f) Monitoring station construction

Figure 26: On-site laying of optical fiber monitoring of the dump.

surface of the slope. In general, the results of numerical analysis are similar to results of the indoor physical model experiment and provide a theoretical basis for field experiments

(3) Through the indoor physical model experiment and numerical simulation results, evolution features of the dump under different working conditions were compared and analyzed in order to lay a theoretical and practical foundation for solutions using fiber optic monitoring of a dump site. Based on this, a fiber optic monitoring design suitable for the site of Dump II was proposed and installed. Monitoring and reporting of the fiber optic network will occur at a later date.

\section{Data Availability}

The data used to support the findings of this study are available from the corresponding author upon request.

\section{Conflicts of Interest}

The authors declare that they have no conflicts of interest.

\section{Acknowledgments}

This work is supported by the National Natural Science Foundation Item of China (No. 41502323) and Beijing Natural Science Foundation of China (8142032).

\section{References}

[1] J. C. Wang and S. W. Sun, Open-Pit Mine Slope Engineering [M], Science Press Ltd, Beijing, 2016.

[2] R. F. Dawson, N. R. Morgenstern, and A. W. Stokes, "Liquefaction flowslides in rocky mountain coal mine waste dumps," Canadian Geotechnical Journal, vol. 35, no. 2, pp. 328-343, 2011.

[3] S. K. Chaulya, R. S. Singh, M. K. Chakraborty, and B. K. Shrivastva, "Quantification of stability improvement of a dump through biological reclamation," Geotechnical \& Geological Engineering, vol. 18, no. 3, pp. 193-207, 2000.

[4] G. Nyamadzawo, F. Mapanda, P. Nyamugafata, M. Wuta, and J. Nyamangara, "Short-term impact of sulphate mine dump rehabilitation on the quality of surrounding groundwater and river water in Mazowe District, Zimbabwe," Physics and Chemistry of the Earth, vol. 32, no. 15-18, pp. 1376-1383, 2007. 
[5] W. P. Huang, C. Li, L. W. Zhang, Q. Yuan, Y. S. Zheng, and Y. Liu, "In situ identification of water-permeable fractured zone in overlying composite strata," International Journal of Rock Mechanics and Mining Sciences, vol. 105, pp. 85-97, 2018.

[6] Y. W. Xu, "Slope protection with vegetation for waste dump at Guangyue road in Shanghai," Advanced Materials Research, vol. 594-597, pp. 465-471, 2012.

[7] D. Verma, A. Kainthola, S. S. Gupte, and T. N. Singh, "A finite element approach of stability analysis of internal dump slope in Wardha valley coal field, India, Maharashtra," American Journal of Mining and Metallurgy, vol. 1, no. 1, pp. 1-6, 2013.

[8] X. S. Liu and M. Xu, "The unsaturated hydromechanical coupling model of rock slope considering rainfall infiltration using DDA," Geofluids, vol. 2017, Article ID 1513421, 15 pages, 2017.

[9] Y. Li, S. Zhang, and X. Zhang, "Classification and fractal characteristics of coal rock fragments under uniaxial cyclic loading conditions," Arabian Journal of Geosciences, vol. 11, no. 9, p. 201, 2018.

[10] Z. Tao, M. Li, C. Zhu, M. He, X. Zheng, and S. Yu, "Analysis of the critical safety thickness for pretreatment of mined-out areas underlying the final slopes of open-pit mines and the effects of treatment," Shock and Vibration, vol. 2018, Article ID 1306535, 8 pages, 2018.

[11] G. H. Sun, S. Lin, W. Jiang, and Y. Yang, "A simplified solution for calculating the phreatic line and slope stability during a sudden drawdown of the reservoir water level," Geofluids, vol. 2018, Article ID 1859285, 4 pages, 2018.

[12] M. Khandelwal and T. N. Singh, "Reclamation of waste dump and its management," in Nat Symp Sustainable Mining Technology, vol. 2002, pp. 313-321, Present \& Future, Chennai, 2002.

[13] F. Arikan, F. Yoleri, S. Sezer, D. Caglan, and B. Biliyul, "Geotechnical assessments of the stability of slopes at the Cakmakkaya and Damar open pit mines (Turkey): a case study," Environmental Earth Sciences, vol. 61, no. 4, pp. 741-755, 2010.

[14] A. Kainthola, D. Verma, S. S. Gupte, and T. N. Singh, "A coal mine dump stability analysis-a case study," Geomaterials, vol. 1, no. 1, pp. 1-13, 2011.

[15] N. Tripathi, R. S. Singh, and S. K. Chaulya, "Dump stability and soil fertility of a coal mine spoil in Indian dry tropical environment: a long-term study," Environmental Management, vol. 50, no. 4, pp. 695-706, 2012.

[16] N. Adibee, M. Osanloo, and M. Rahmanpour, "Adverse effects of coal mine waste dumps on the environment and their management," Environmental Earth Sciences, vol. 70, no. 4, pp. 1581-1592, 2013

[17] S. P. Pradhan, V. Vishal, T. N. Singh, and V. K. Singh, "Optimisation of dump slope geometry vis-à-vis fly ash utilisation using numerical simulation," American Journal of Mining \& Metallurgy, vol. 2, no. 1, pp. 1-7, 2014.

[18] B. Poulsen, M. Khanal, A. M. Rao, D. Adhikary, and R. Balusu, "Mine overburden dump failure: a case study," Geotechnical \& Geological Engineering, vol. 32, no. 2, pp. 297-309, 2014.

[19] G. W. Ma, "Stability analysis of Jinduicheng open-pit mine's dump," Metal Mine, vol. 8, pp. 32-34, 2004.

[20] Y. S. Song, Y. C. Cho, and S. Hong, "Analyses on variations in the unsaturated characteristics of a mine waste-dump slope during rainfall," Environmental Earth Sciences, vol. 75, no. $14,2016$.

[21] L. Zhang, J. M. Wang, Z. K. Bai, and C. Lv, "Effects of vegetation on runoff and soil erosion on reclaimed land in an opencast coal-mine dump in a loess area," Catena, vol. 128, pp. 44-53, 2015.

[22] J. C. Wang and C. Chen, "Stability analysis of slope at a disused waste dump by two-wedge model," International Journal of Mining, Reclamation and Environment, vol. 31, no. 8, pp. 575-588, 2016.

[23] V. Ranjan, P. Sen, D. Kumar, and A. Saraswat, "Enhancement of mechanical stability of waste dump slope through establishing vegetation in a surface iron ore mine," Environmental Earth Sciences, vol. 76, no. 1, p. 35, 2017.

[24] L. Han, J. Shu, Q. Cai, H. Jing, and H. Tian, "Mechanical characteristics of dip basement effects on dump stability in the Shengli open pit mine in Inner Mongolia, China," Arabian Journal of Geosciences, vol. 9, no. 20, p. 750, 2016.

[25] Y. C. Cho and Y. S. Song, "Deformation measurements and a stability analysis of the slope at a coal mine waste dump," Ecological Engineering, vol. 68, no. 7, pp. 189-199, 2014.

[26] Y. Sun, H. Xu, P. Gu, and W. Hu, "Application of FBG sensing technology in stability analysis of geogrid-reinforced slope," Sensors, vol. 17, no. 3, p. 597, 2017.

[27] Z. Chun, T. Zhigang, Y. Sen, and Z. Shuai, "V shaped gully method for controlling rockfall on high-steep slopes in China," Bulletin of Engineering Geology and the Environment, 2018.

[28] M. Schallert, W. R. Habel, and D. Hofmann, "Analysis of concrete foundation piles using structure-integrated fibre-optic sensors," Technisches Messen, vol. 75, no. 9, pp. 485-500, 2008.

[29] C. D. Piao, B. Shi, and Y. Zhu, "Experimental study on BOTDR temperature compensation in bored pile detection," Journal of Disaster Prevention \& Mitigation Engineering, vol. 29, no. 2, pp. 161-164, 2009.

[30] A. Klar and R. Linker, "Feasibility study of automated detection of tunnel excavation by Brillouin optical time domain reflectometry," Tunnelling and Underground Space Technology, vol. 25, no. 5, pp. 575-586, 2010.

[31] W. R. Habel and K. Krebber, "Fiber-optic sensor applications in civil and geotechnical engineering," Photonic Sensors, vol. 1, no. 3, pp. 268-280, 2011.

[32] H. Zhang and Z. S. Wu, "Performance evaluation of PPPBOTDA-based distributed optical fiber sensors," International Journal of Distributed Sensor Networks, vol. 8, no. 12, Article ID 414692, 2012.

[33] H. Xiao and J. Huang, "Experimental study of the applications of fiber optic distributed temperature sensors in detecting seepage in soils," Geotechnical Testing Journal, vol. 36, no. 3, article 20120096, 2013.

[34] H. Naruse, H. Uehara, T. Deguchi et al., "Application of a distributed fibre optic strain sensing system to monitoring changes in the state of an underground mine," Measurement Science and Technology, vol. 18, no. 10, pp. 3202-3210, 2007.

[35] T. Kogure and Y. Okuda, "Monitoring the vertical distribution of rainfall-induced strain changes in a landslide measured by distributed fiber optic sensing with Rayleigh backscattering," Geophysical Research Letters, vol. 45, no. 9, pp. 4033-4040, 2018. 

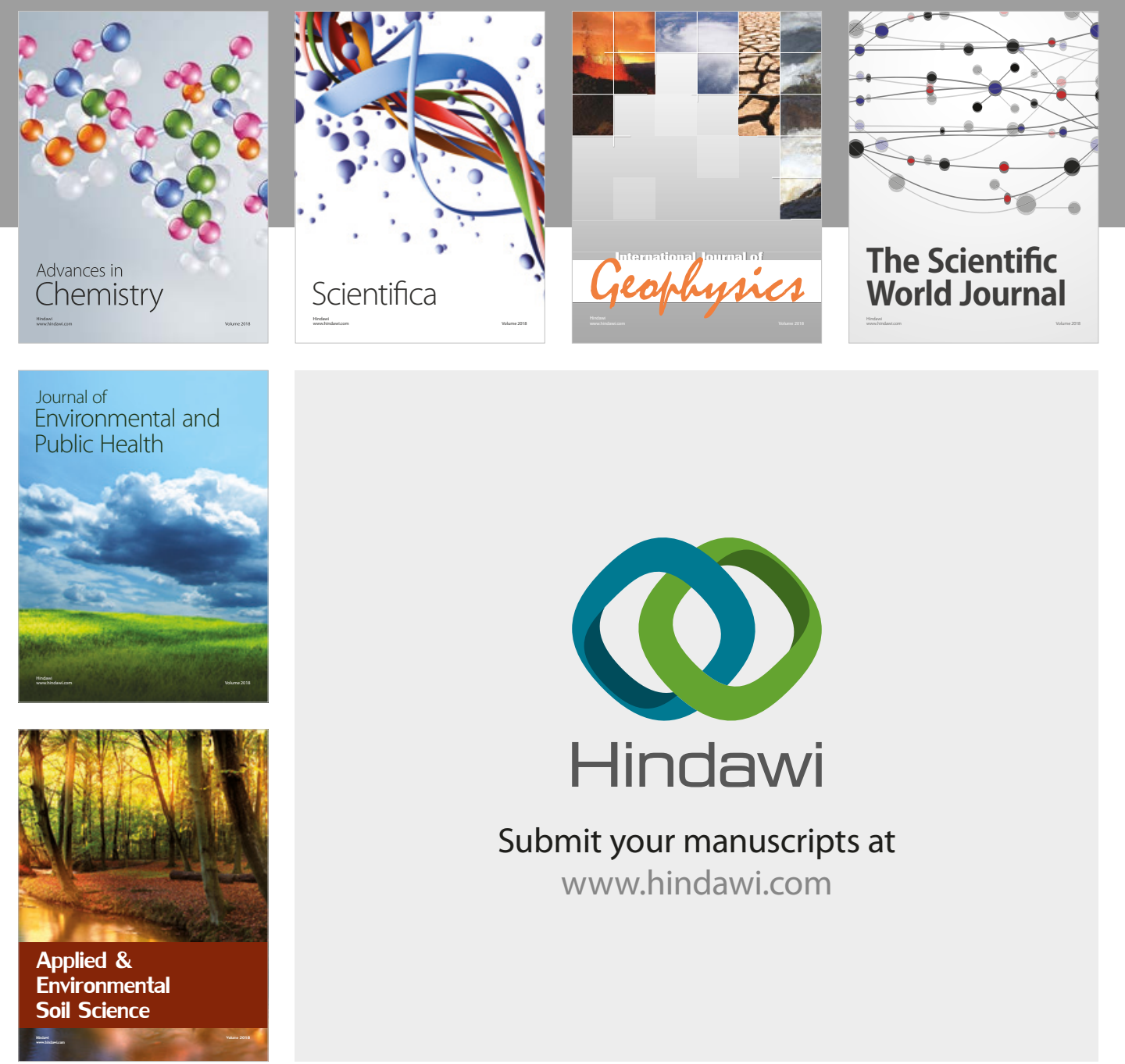

The Scientific

\section{World Journal}
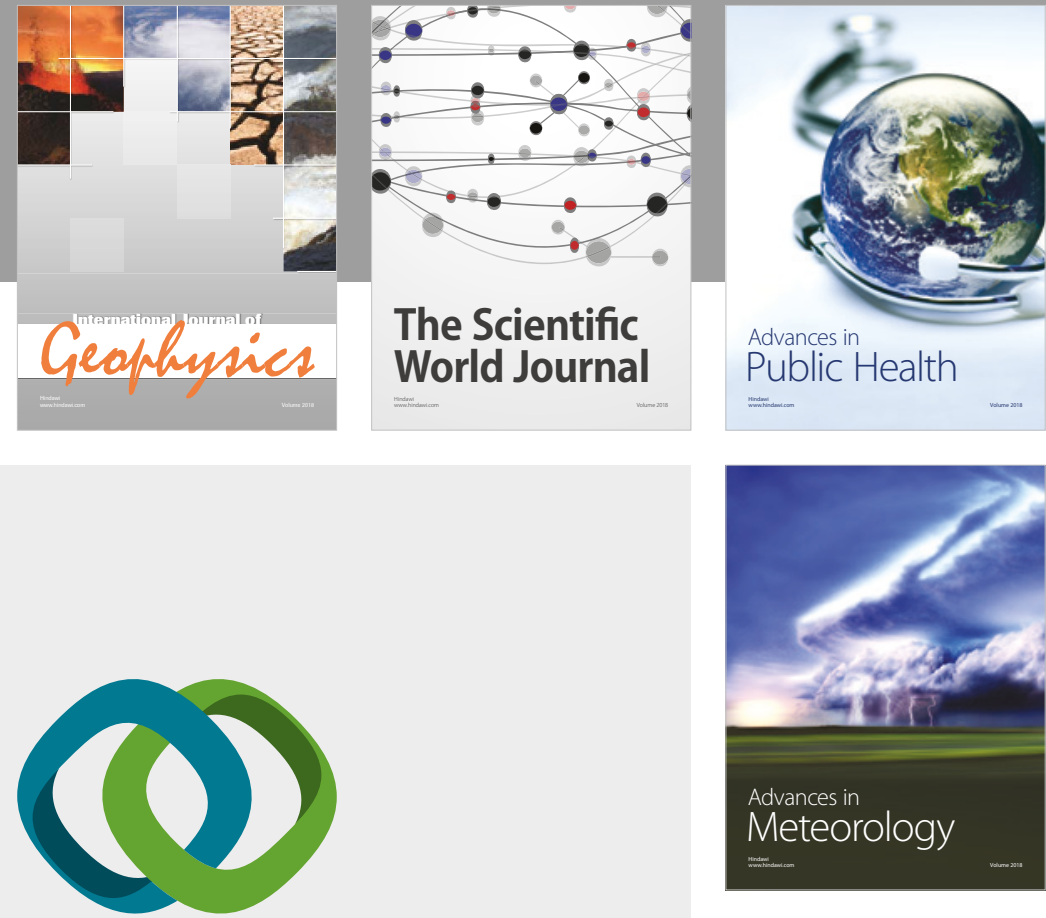

Advan

Public Health

\section{Hindawi}

Submit your manuscripts at

www.hindawi.com
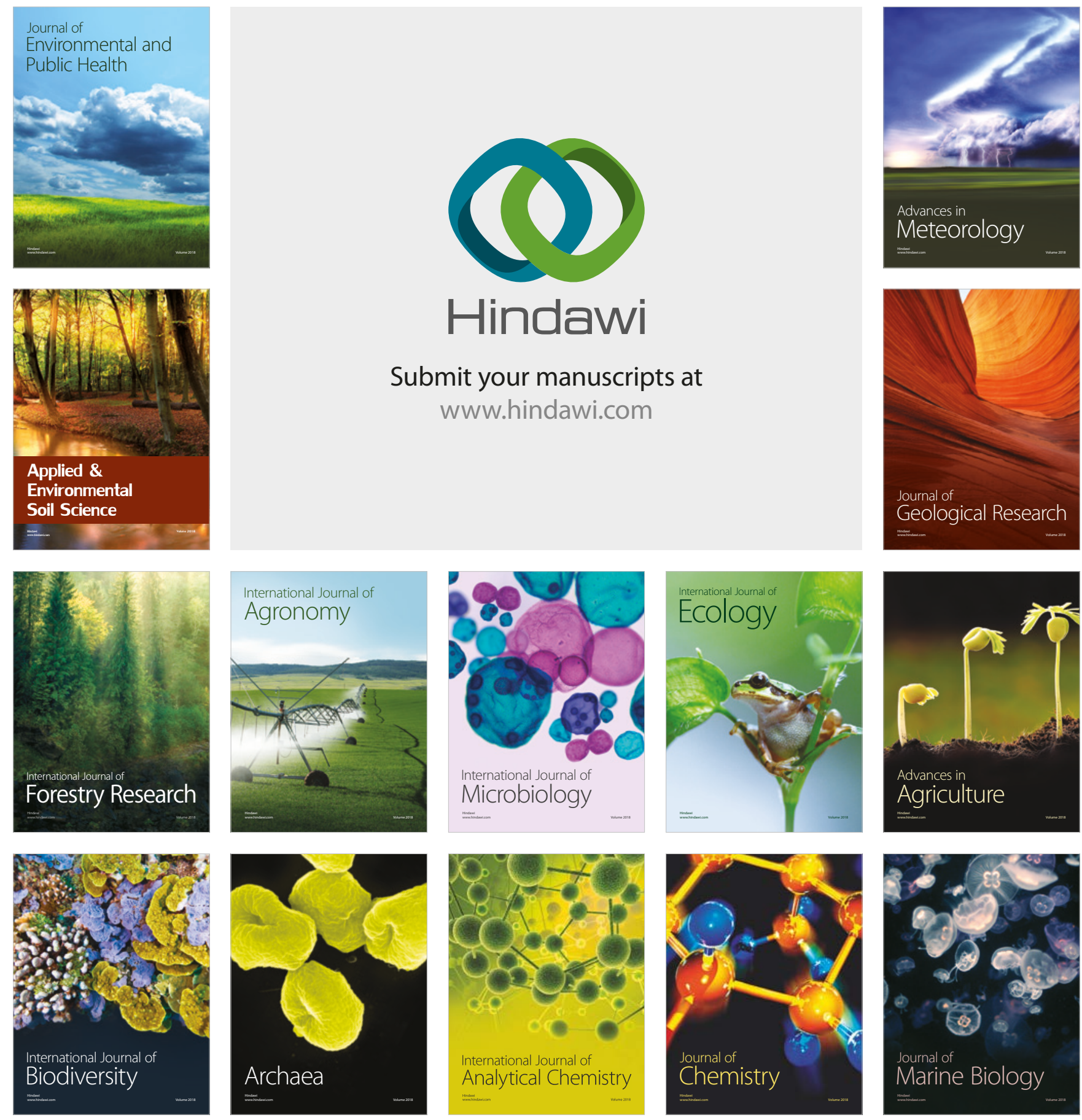